\title{
Para un concepto de no lineal de Historia. Reflexiones a partir de Walter Benjamin
}

\section{For a non lineal concept of History. Reflections on the basis of Walter Benjamin's philosophy}

\section{Para um conceito não-linear de História. Reflexões a partir de Walter Benjamin}

Stefan Gandler*

Universidad Autónoma de Querétaro, Facultad de Ciencias Políticas y Sociales, Mexico

\begin{abstract}
RESUMEN
El punto de partida de este estudio es el último texto de Walter Benjamin, sus Tesis "Sobre el concepto de historia". Benjamin apela a la importancia de la teología para el materialismo histórico con la intención de poder superar una de las razones decisivas por las que el proyecto teórico único de Marx -en sus interpretaciones positivistas- no ha sido entendido con la necesaria radicalidad y ha estado en peligro de perder su fuerza explicativa y su impulso revolucionario. La necesidad de mirar hacia atrás, hacia lo que llamamos el pasado, constituye el tema central del estudio, y se analiza a nivel epistemológico, ontológico y político. La mirada hacia atrás es también necesaria porque el pasado demuestra cómo todas las atrocidades, que pensamos han sido superadas, pueden volver en cualquier momento de una manera que no podemos imaginar.
\end{abstract}

Palabras claves: Historia, Concepto de Progreso, Concepto de Tiempo, Concepto de Historia no lineal, Walter Benjamin, Teoría crítica (no eurocéntrica)

\begin{abstract}
The point of departure of this study is Walter Benjamin's last text Theses on the Philosophy of History. Benjamin appeals to the significance of theology for historical materialism in order to overcome one of the decisive reasons why Marx's unique theoretical project - in its positivistic interpretations - was not understood with the necessary radicalness and has been in danger to lose its explanatory power and revolutionary impulse. The necessity of looking back to the past constitutes the basic theme of the study, and it is analyzed at the epistemological, ontological and political levels. The view backwards is also necessary because the past shows how all its atrocities, which we think have been overcome, may at any time return in a way which we are unable to imagine.
\end{abstract}

Keywords: History, Concept Progress, Concept Time, Concept Non lineal history, Walter Benjamin, Critical Theory (non Eurocentric) 


\begin{abstract}
RESUMO
O ponto de partida deste estudo é o mais recente texto de Walter Benjamin, sua tese "Sobre o conceito de história". Benjamin apela para a importância da teologia para o materialismo histórico, com a intenção de superar uma das razões decisivas porque o projeto único da teoria de Marx, em suas interpretações positivistas, não foi entendido com a necessária radicalidade e estava em risco de perder seu poder explicativo e seu impulso revolucionário. A necessidade de olhar para trás, em direção ao que chamamos de passado, é o foco do estudo, e é analisada no nível epistemológico, ontológico e político. O olhar para trás também é necessário porque o passado mostra como todas as atrocidades, que pensamos ter superado, podem voltar a qualquer momento em uma maneira que não podemos imaginar.

Palavras-chave: História, Conceito de progresso, Noção de tempo, Conceito não-linear da história, Walter Benjamin, Teoria crítica (não-eurocêntrica)
\end{abstract}

\title{
I ntroducción
}

El tema central de este artículo es una contribución a la comprensión filosófica que Walter Benjamin elabora en sus tesis Sobre la filosofía de la historia de los conceptos de historia, progreso y tiempo, sin limitar su radicalidad teórica, como se hace en la mayoría de las interpretaciones académicas de su obra hoy. La confrontación directa que realiza Benjamin entre materialismo y mesianismo no es un auto malentendido de Benjamin, y no es tampoco una mezcla más o menos confusa de ambos, sino que es el centro argumentativo de la respuesta que él da a una de las cuestiones filosóficas más importantes de nuestra época: ¿cómo puede el carácter ideológico, manipulador y tendencialmente represivo de los sistemas metafísicos heredados -especialmente las religiones dominantes ser superado sin caer en un nuevo sistema filosófico ideológico, manipulante y tendencialmente represivo, el positivismo $y$ sus versiones renombradas y remasterizadas contemporáneas, que nos hacen incapaces de entender realmente y de poder cambiar la actual existente forma auto destructiva de reproducción y de organización social?

\section{Tres razones para leer a Benjamin hoy}

Hay actualmente por lo menos tres razones por las que el texto "Über de Begriff der Geschichte" de Walter Benjamin ["Sobre el concepto de historia"] $^{1}$ debe ser releído directamente, superando algunas limitaciones implícitas que fueron establecidas por diversos intérpretes desde su primera publicación. La más importante de estas limitaciones es el acuerdo secreto existente (en los términos de Benjamin) de evitar cualquier discusión de su crítica radical del concepto existente de tiempo como homogéneo, ininterrumpido, y claramente dirigido. Benjamin, que 
en este punto entiende mejor El capital de Marx que la mayoría de los otros marxistas, afirma que solamente una crítica radical de la categoría de organización central de la vida cotidiana bajo la forma de reproducción capitalista, a saber: tiempo universal, puede ayudar a derrotar la energía ideológica del pensamiento positivista en la forma capitalista de "organización social."

\section{La primera razón para leer a "Sobre el concepto de historia" de} Benjamin hoy es la necesidad renovada de mejorar "nuestra posición en la lucha contra el fascismo" (BENJ AMIN, tesis VIII, 2008, p. 43), que era el incentivo político central para la producción teórica de Benjamin en los sus últimos años. Esta lucha contra el fascismo tiene hoy más actualidad que en cualquier otro momento desde 1945. Las fuerzas políticas de extrema derecha son de más grande alcance que nunca desde el final militar de la época nacional-socialista/fascista en Europa, y en algunas partes de América Latina encuentra más simpatía popular que nunca desde la superación de las dictaduras militares de extrema derecha del siglo pasado. Chile e Italia son solamente dos ejemplos en donde la relación personal, política e ideológica directa con los viejos grupos fascistas no sólo no representa un problema político para partes importantes de los votantes, sino que incluso parece producir cierta confianza en algunas mentes. Al mismo tiempo, diversos grupos de la izquierda política no entienden el peligro presente en gobiernos y movimientos de extrema derecha como en el Irán de hoy. En ambos casos, una idea ingenua de progreso ayuda a la extrema derecha y ciega a grupos izquierdistas al peligro actual.

\section{La segunda razón para leer a "Sobre el concepto de historia" de} Benjamin hoy es que para la comprensión de la realidad social política, económica y de las relaciones culturales a nivel mundial, es necesario desarrollar una Teoría crítica matizada que supere limitaciones eurocéntricas. Estas limitaciones, que han marcado la Teoría crítica desde su inicio, las comparte con las otras teorías y filosofías sociales que existen en el supuesto primer mundo (hoy: G8, G20 etcétera), y extienden su influencia al llamado Tercer mundo (hoy también: países emergentes etcétera), la idea sigue siendo la misma que aquella mantenida en la guerra fría). La crítica radical de Walter Benjamin de la idea del tiempo como homogéneo, continuo y claramente dirigido; las consecuencias teóricas resultantes que formula a partir de esta idea central; y su crítica de la ideología del 'progreso como norma' es una sólida base filosófica para la reconstrucción de la Teoría crítica en términos no-eurocéntricos. La crítica de la creencia predominante del 
'progreso como norma' redefine no sólo la relación entre el 'pasado' y el 'presente' - en términos de tiempo- sino también reorganiza -en términos de espacio- la relación entre diferentes 'desarrollos' culturales, sociales e incluso técnicos. La implícita idea ingenua del progresismo es que hay solamente un avanzar unidireccional en el proceso capitalista y que la única diferencia entre las diversas regiones en el mundo es el grado de progreso sobre este único camino que ha logrado cada una. Partiendo de esta contribución de Benjaminiana, el "acuerdo entre caballeros eurocéntrico" entre la mayoría de los filósofos contemporáneos y de los teóricos sociales de tendencias políticas muy diversas, puede ser criticado sin caer en la -también académicamente popular- ideología de las 'identidades auténticas' que 'deben ser defendidas por cualquier medio contra el imperialismo (cultural)'.

Incluso algunos miembros de la original Escuela de Frankfurt tendieron a reducir la crítica de Benjamin de la ideología del progreso a una crítica de la falsa identificación entre el progreso tecnológico y el progreso humano, pero sus conceptos de tiempo e historia son mucho más radicales que la mayor parte de sus intérpretes contemporáneos quieren admitir. Con esta reducción, la puerta filosófica que Benjamin ha abierto hacia una comprensión no linear de la historia (en términos de tiempo y espacio) corre el peligro de cerrarse nuevamente. La intención de este artículo, entonces, es reabrir esa puerta conceptual como contribución central para la construcción absolutamente necesaria de una Teoría crítica no eurocéntrica. ${ }^{2}$

\section{La tercera razón para leer a "Sobre el concepto de historia" de} Benjamin hoy es que este texto es uno de los mejores textos filosóficos escritos en la tradición occidental y no ha perdido su fuerza explosiva para la comprensión de las relaciones sociales de hoy. Al mismo tiempo, este texto y su verdad están siempre en peligro de ser perdidos $\mathrm{u}$ olvidados, también hoy cuando se habla y escribe mucho sobre él. Solamente si entendemos que el texto habla de nosotros, si nos reconocemos a nosotros, nuestra historia, nuestro propio, momento histórico del presente como aquello de lo que Benjamin está hablando, podemos evitar ser parte de la máquina que hace que todo 'siga adelante', alejándonos de la posibilidad de poder trabajar sobre este momento y de entenderlo.

Una idea central de la forma predominante (finalmente positivista) del trabajo científico y académico es aquella que nos dice que tenemos que 'estar actualizados', haber leído las últimas 'novedades académicas' y, si queremos hablar sobre Benjamin, comenzar con un reconocimiento de los últimos artículos y libros escritos sobre su trabajo. Pero la crítica de 
Benjamin no sólo se dirige hacia el ingenuo progresismo político e histórico, sino también hacia la idea simple de un progreso casi automático en el proceso epistémico y la 'acumulación irreversible de conocimientos'. Es decir: un texto escrito en 2010 no es necesariamente más 'actual' que un texto escrito en 1940. El mejor acceso a un texto podría a veces ser el de establecer una conexión teórica directa entre la situación material, social e intelectual de hoy con - en este caso aquella de Europa y Benjamin en la época del fascismo y del nacional socialismo.

El texto de Benjamin se puede considerar como uno del más elaborados en la historia de la filosofía occidental, porque este texto abre más perspectivas que cualquier otro texto para entender los errores filosóficos e ideológicos centrales de los antifascistas en los años treinta y cuarenta del siglo pasado que impidieron parar el nacional socialismo y los fascismos de aquel momento. Si alguna obra podría compararse en su fuerza reveladora con las tesis Sobre el concepto de historia, sería Shoah de Claude Lanzmann. No es un escrito, es una película -sus medios de expresión son totalmente diferentes de aquellos de las Tesis de Benjamin -, y al mismo tiempo son algo como gemelos filosóficoartísticos.

No es por casualidad que el director de Shoah es al mismo tiempo el editor da la revista Les temps modernes, fundada por Sartre y de Beauvoir, que era el lugar en donde las Tesis de Benjamin fueron publicadas por primera vez. Hay algo como un acuerdo secreto entre el combatiente de la Résistance, periodista, filósofo y cineasta judío francés Claude Lanzmann y el especialista del arte, traductor del francés al alemán, filósofo y amante de la ciudad de París judío alemán Walter Benjamin. Quizás, el único lugar donde están materialmente presentes las Tesis de Benjamin hoy es en la película Shoah.

\section{Angelus Novus}

La siguiente interpretación del texto "Über den Begriff der Geschichte [Sobre el concepto de historia]" de Walter Benjamin sigue dos ejes principales. El primero parte de su contexto filosófico, y el segundo de su contexto histórico.

Filosóficamente no queda la menor duda que el texto sólo se puede entender si se parte del hecho de que es un escrito radicalmente materialista. Es un intento por radicalizar al materialismo crítico, no mecanicista de Marx. Esta radicalización filosófica es necesaria debido al contexto histórico durante el cual Walter Benjamin lo escribe: el nacionalsocialismo en Alemania y el fascismo en gran parte de Europa, que coinciden con el fracaso de la izquierda en estos paises. Es posible 
esta radicalización (en el sentido de llegar más cerca de las raíces de las relaciones y contradicciones existentes) del materialismo histórico, con la ayuda que Benjamin toma prestada de ciertos aspectos de la teología. El materialismo histórico de Benjamin pone a su servicio la teología, no para suavizar filosóficamente su crítica a las relaciones sociales existentes y acercarlo políticamente a la ideología burguesa. Al contrario: el materialismo histórico en la versión predominante durante la época de Walter Benjamin - como lo desarrollaron los teóricos de la socialdemocracia - se había acercado bastante a doctrinas burguesas, y con la ayuda de la teología podría superar la limitación de su radicalidad. El punto clave en este sentido es el concepto de tiempo ${ }^{3}$, que fue retomado de manera ingenua desde la tradición establecida por la mayoría de los marxistas. Mientras que en la física ya había, por parte de Albert Einstein, una crítica radical a este concepto de tiempo como algo que avanza inmutablemente, en la filosofía, todavía no había un intento serio de superar este concepto simplista.

Marx todavía no pudo desarrollar esta crítica, en su época, con la misma radicalidad con la cual la desarrolla Benjamin, pero en su crítica al concepto de valor, desarrollado por la economía política, está ya implícito el germen para esta crítica. El pensamiento burgués, que en la física acepta por fin - con ciertas excepciones - la ruptura epistemológica que representa la teoría de la relatividad de Einstein, no lo hace en el terreno filosófico y de ciencias sociales. En la física no le queda otra opción, debido a las innegables ventajas en las aplicaciones técnicas que surgen a partir de la teoría de la relatividad, sobre todo en la física nuclear y en la astronomía, como por ejemplo en los viajes espaciales. Pero en la filosofía y las ciencias sociales, esta ruptura epistemológica es impensable para el pensamiento burgués. ¿Por qué? Porque, como demostró Marx, la economía capitalista se basa necesariamente sobre el concepto del tiempo como algo lineal e inmutable. Esta concepción es ciertamente sagrada para la ideología dominante, porque el tiempo es la única medida que tiene la forma económica existente hoy en día prácticamente sobre toda la tierra, para comparar lo que en sí es incomparable: el trabajo distinto de seres humanos distintos.

La clásica división de la razón en la sociedad burguesa, analizada por la escuela de Frankfurt, por ejemplo en la Dialéctica de la ilustración de Max Horkheimer y Theodor W. Adorno, en la razón instrumental que se desarrolla sin límites y la razón en el sentido amplio y clásico como lo usa por ejemplo G. W. F. Hegel, o dicho de otro modo, en la razón subjetiva y la razón objetiva, se presenta también en el problema del concepto de tiempo. Mientras la razón instrumental se aprovecha en 
términos técnicos y prácticos de los grandes descubrimientos de Einstein, la razón objetiva está tan estancada en esta formación social, que no se encuentra en condiciones de cuestionar el concepto de tiempo en la vida cotidiana a partir de estos descubrimientos. ${ }^{4}$

Con la aceptación de la teoría de la relatividad para la filosofía y las ciencias sociales, se derrumbaría sin piedad todo el orden existente. Marx preparó el terreno teórico en el cual Benjamin hace esta gran revelación a la cual llega con la ayuda de ciertos métodos y herencias de la teología. La revelación de Benjamin es estrictamente materialista porque se basa en el conocimiento de que, el tiempo como algo lineal, ininterrumpido y con dirección definida, es una construcción ideológica que no se basa en ningún sustento material. Es la puerta de salida de este sistema político-económico y social aparentemente sin salida, sin la necesidad de una salvación mesiánica - en el sentido clásico de la palabra, como una salvación que viene de afuera de la sociedad.

Paradójicamente es justamente la teología, la que ayudó a Benjamin a poder superar la necesidad de elementos no humanos para poder pensar o imaginarse esta salida. El elemento mesiánico que sí existe en el texto de Benjamin, es uno bien diferente de las ideas clásicas de salvación mesiánica que existen en muchas religiones e implícitamente también en muchas de las interpretaciones limitadas del materialismo histórico del concepto de revolución. Para Walter Benjamin existe una "débil fuerza mesiánica" (BENJAMIN, tesis II, 2008, p. 37) en cada generación de seres humanos que puede hacerse virulenta justamente a partir del conocimiento de un concepto diferente del tiempo, es decir a partir del entendimiento de que el pasado está presente, de una manera muy diferente de lo que pensamos por lo general, en el presente: "éramos esperados sobre la tierra" (BENJ AMIN, tesis II, 2008, p. 37) por las generaciones anteriores. Mientras que en diferentes religiones se espera el Mesías y mientras que en las interpretaciones limitadas del materialismo histórico se espera un acto mesiánico que viene de fuera de la sociedad o del 'cumplimiento de las leyes de la historia' que en última instancia no es otra cosa que la esperanza a un Mesías, Benjamin traslada la esperanza de las generaciones anteriores a una que se dirige hacia nosotros.

El único instrumento que puede 'medir' el tiempo son los relojes, que en verdad no hacen otra cosa que medir su propio ritmo auto producido, o dicho en otras palabras: los relojes no son otra cosa que contadores de oscilaciones anteriormente producidas con la intención de tener un movimiento que se repite en lo ideal eternamente con las mismas características. La idea de la repetición de momentos cualitativamente iguales es la base de construcción de los relojes que a su vez nos 
sugieren la existencia objetiva de este tiempo lineal, meramente cuantitativo y sin cualidades específicas. Esta idea del tiempo lineal es relativamente vieja, pero alcanza su fuerza actual con la aparición de relojes cada vez más exactos y baratos, es decir omnipresentes y con la forma económica que se basa exclusivamente sobre el aspecto cuantitativo del valor o del tiempo lineal.

Aparentemente, justo en el momento de la generalización de esta forma de producción, se llegó a medir el tiempo de manera más exacta y por esto se logró tener a los horarios cada vez más unificados, a grandes escalas geográficas, así como antes se había unificado el calendario, después de una lucha por siglos entre distintos sistemas calendarios, hasta que quedó por fin el gregoriano como el dominante casi a escala mundial. $^{5}$ Pero el movimiento fue más complejo: esta forma social necesitaba de estas formas más exactas y más generalizadas para medir el tiempo según sus reglas. En una relación dialéctica entre el desarrollo de las técnicas de medir este tiempo y la necesidad social de medirlo de tal manera, así como de la capacidad política-organizativa de imponer este nuevo tiempo entre la sociedad, se llegó a una forma de percibir el tiempo y poder medirlo de la manera correspondiente.

En la supuesta homogeneidad del tiempo está también presente una de las fuerzas del etnocentrismo en su forma dominante hoy en día: el eurocentrismo. Negando el aspecto cualitativo del tiempo, concibiéndolo como "vacío" (BENJ AMIN, tesis XIII, 2008, p. 51), se le pone fuera de la decisión colectiva y social, y absolutiza o naturaliza con esto ciertas tradiciones locales con su respectiva valoración cualitativa del tiempo (que en términos reales siempre existe, a pesar de ser sistemáticamente segado). El día domingo es entonces, fuera de toda discusión, día festivo fijo en la mayoría de los paises, así como ciertos horarios de comida, descanso y trabajo. Lo que desde el punto de vista del ethos realista, que tiene plena presencia en el llamado primer mundo, es una forma inexacta o menos seria de actuar en relación al tiempo que se percibe como algo objetivamente dado, podría ser entendido entonces, de otra manera. Probablemente, se trata de una forma diferente o propia de construir y concebir el tiempo, perteneciente a otro tipo de modernidad. No se le puede juzgar o entender a partir de la construcción ideológica del tiempo que se tiene en ciertos paises. Es decir, criticar el concepto dogmático del tiempo lineal y homogéneo como algo supuestamente natural o dado eternamente, podría abrir el camino a una crítica radical del etnocentrismo del noroeste europeo y estadounidense. En referencia a la afirmación de Benjamin, de que una crítica al progresismo político y teórico sólo es posible si se basa en una crítica del concepto dogmático del tiempo, se podría llegar a la 
conclusión, de que una crítica al eurocentrismo sólo es posible si se basa igualmente en una crítica del concepto realista del tiempo. ${ }^{6}$ Ahí estaría por consiguiente un punto de enlace decisivo entre la teoría del cuádruple ethos de la modernidad capitalista (con especial énfasis en el ethos barroco) de Bolívar Echeverría, y la crítica al concepto de tiempo lineal desarrollada por Walter Benjamin.

Después de esta pequeña nota preliminar sobre el contexto (filosófico e histórico), la radicalidad y las posibles consecuencias de la teoría del tiempo presente ("Jetztzeit") en el texto sobre el concepto de historia de Benjamin, queremos abordar desde distintos ángulos, la pregunta de ¿Por qué el Ángel de la Historia mira hacia atrás?

Esta pregunta, a partir de la cual queremos organizar nuestras siguientes interpretaciones del texto "Über den Begriff der Geschichte [Sobre el concepto de historia]" de Walter Benjamin, se puede enfatizar de dos maneras. La primera y la más obvia sería: ¿Por qué el Ángel de la Historia mira hacia atrás? Y la segunda manera sería: ¿Por qué el Ángel de la Historia mira hacia atrás?

\section{¿Por qué el Ángel de la Historia mira hacia atrás?}

Vamos a empezar con esta segunda forma de acentuar la pregunta que es a la vez, la pregunta sobre el papel que juega la teología en estas notas de Benjamin. ¿Por qué es justamente un ángel la figura que mira hacia atrás? ¿Por qué no un sabio, un filósofo, un comité central o el espíritu universal? El "Ángel de la Historia", "der Engel der Geschichte" (Benjamin, tesis IX, 2008, p. 44 y s.) del cual habla Benjamin en la tesis $\mathrm{IX}$, es sin lugar a dudas más que una mera referencia a la imagen de Paul Klee, titulada "Angelus Novus"7. Esta formulación en la tesis IX, se encuentra en directa relación con la primera tesis, en la cual Benjamin menciona la importancia que tiene la teología para el materialismo histórico, al que él se propone aportar algo relevante en una época de su profunda crisis. Antes que nada es importante subrayar que Benjamin no propone abandonar el materialismo histórico para dirigirse hacia la teología. Tampoco sugiere mezclar el materialismo histórico con la teología como si fueran dos componentes de la misma categoría. Más bien, está muy claro que se trata de poner la teología al servicio del materialismo histórico, para que este gane en contra de cualquier retador.

“En la filosofía, uno puede imaginar un equivalente de ese mecanismo; está hecho para que venza siempre el muñeco que conocemos como 'materialismo histórico'. Puede competir sin más con cualquiera siempre que ponga a su servicio a la teología, la misma que hoy, como se sabe, además de ser 
pequeña y fea, no debe dejarse ver por nadie." (BENJAMIN, tesis I, 2008, p. 35).

Pero ¿cual es el retador más temido? ¿A quién tiene que enfrentarse el materialismo histórico en el momento que Benjamin apunta estas líneas? El autor lo dice justamente en la tesis que a su vez es la única, aparte de la citada primera tesis en la cual hace una referencia explícita a la teología. En la tesis X, en la cual toma cierta regla de conducta de los monjes como ejemplo a seguir, precisa este momento histórico:

“En un momento en que los políticos, en quienes los adversarios del fascismo habían puesto su esperanza, yacen por tierra y refuerzan su derrota con la traición a su propia causa, esta reflexión se propone desatar al que vive en el mundo de la política de las redes en que ellos lo han envuelto." (BENJAMIN, tesis $X, 2008$, p. 45).

En este momento, al autor propone seguir el ejemplo de los hermanos:

“Los temas de meditación que la regla conventual proponía a los hermanos novicios tenían la tarea de alejarlos del mundo y sus afanes. La reflexión que desarrollamos aquí procede de una determinación parecida." (BENJ AMIN, tesis X, 2008, p. 45).

Esta es una de las cosas que Benjamin piensa poder aprender de la teología: la capacidad de tomar distancia de lo inmediato de las actividades del mundo, una capacidad que por lo general no se puede desarrollar por el politicismo de la izquierda. Esto es, en el tiempo del nacionalsocialismo y fascismo, nada obvio, ya que, como se puede entender en la frase arriba citada, es muchas veces justamente la falta de distancia hacia la propia derrota lo que desemboca en la traición a la propia causa. La enseñanza que Benjamin quiere retomar de la teología, tomada en servicio por el materialismo histórico, es la siguiente. Lo que hoy en día existe visiblemente no es la totalidad, no es la última palabra de la historia, hay algo fuera de la fuerza destructora casi omnipresente en la contemporaneidad de Benjamin. Es la desesperanza que predominaba en esa época, según muchos testimonios, entre los no fascistas y no nacionalsocialistas, en contra de la cual Benjamin retoma la vieja idea teológica de la esperanza, ${ }^{8}$ aunque por supuesto él mismo, se prohíbe hacerlo con la inmediatez de Bloch. Según esta perspectiva, es este último texto de Walter Benjamin antes de su suicidio, todo menos que el documento de la desesperanza de alguien que está a punto del auto homicidio, como la había interpretado en alguna ocasión José María Pérez Gay. 
Una de las razones principales por la cual Benjamin se refiere a la teología es, entonces, su impulso radicalmente crítico y revolucionario, entendido en el sentido de que lo que aparentemente es una realidad de la cual en tiempos próximos no podremos salir ("el imperio de los mil años"), no es la totalidad de lo existente. Hay algo más de lo que se impone con poder sangriento. (Obviamente una gran parte de los religiosos y creyentes por ejemplo, en la Alemania de esta época no supieron entender la teología así y se sometieron de manera incondicional al proyecto destructivo nacionalsocialista. Es por esto que Benjamin afirma en la primera tesis que la teología "hoy, como se sabe, además de ser pequeña y fea, no debe dejarse ver por nadie." BENJ AMIN, tesis I, 2008, p. 35). Este tomar distancia del mundo en su realidad actual no significa para Benjamin un retirarse de las luchas reales hacia una nueva actitud meramente contemplativa que implícitamente está en complicidad con la realidad dominante al no tocarla, así como se ha hecho en muchas de las interpretaciones 'pequeñas' de la teología. Las reflexiones de Benjamin intentan - como dice enseguida después de la mención de las reglas de los conventos: "desatar al que vive en el mundo de la política de las redes en que ellos [estos políticos, S.G.] lo han envuelto." (BENJAMIN, tesis X, 2008, p. 45).

Pero la radicalidad en la comprensión de lo existente, que Benjamin quiere profundizar poniendo al servicio del materialismo histórico a la teología, va más allá de la forma de ver o enfrentarse al fascismo y nacionalsocialismo. Nos referimos aquí al punto más radical de este conjunto de notas de Benjamin, que ya mencionamos en las notas preliminares: La crítica al concepto dominante hoy en día del tiempo como continuo y lineal. En la teología existe también la idea de la posibilidad y necesidad de interrumpir el continuum temporal. Existe en ella también la idea de que hay algo más allá, no solamente de lo que hoy en día se impone materialmente, sino además algo fuera de las bases conceptuales más profundas y menos cuestionadas de la formación social actualmente imperante.

La diferencia entre la teología y lo que retoma Benjamin de ella consiste en que Benjamin ve la posibilidad de esta ruptura dentro de este mundo. El "J etztzeit" [tiempo del ahora] (BENJ AMIN, tesis XIV, 2008, p. 51), no es el juicio final y no hay que esperar la propia muerte para poder acercarse a esta nueva concepción del tiempo. La experiencia y praxis de muchas generaciones en sus actos de memoria y tradiciones vivas tienen en sí algo central de esta concepción del 'tiempo del ahora'. Un ejemplo podría ser en la arquitectura religiosa el Baptisterio de Florencia del siglo once o doce. Su forma octangular puede ser 
interpretada como una referencia a un "octavo día", es decir el día, el tiempo fuera del tiempo normal, lineal.

El materialismo histórico tenía con Karl Marx un pensador que superó en muchos aspectos lo heredado por el materialismo mecánico y el idealismo. Pero esta base teórica, en muchos sentidos única, no fue retomada por largo tiempo con la radicalidad necesaria con la que la fundó Marx. Benjamin recurre a la teología para poder superar una de las razones principales de por qué el proyecto de Marx, a lo largo del tiempo, perdió tanta fuerza explicativa y tanto impulso revolucionario: las tendencias positivistas que existían de igual manera en la interpretación de los teóricos de corte socialdemócrata así como de corte estalinista ${ }^{9}$. La profunda convicción de los religiosos de que lo visible no es el todo, y el poder existente actualmente no el único, es lo que, como tratamos de demostrar, retoma Benjamin de la tradición teológica, sin querer retomar el impulso que hace pequeña y fea a la teología: el de sacrificar justamente estos conocimientos para poder vivir con lo que Benjamin rechaza tanto: el conformismo. (Véase BENJ AMI N, tesis XI, 2008, p. 46).

Por esto es el Ángel de la Historia quien mira hacia atrás.

Vamos ahora al segundo modo de entender nuestra pregunta:

\section{¿Por qué el ángel de la historia mira hacia atrás?}

El ángel de la historia en las tesis de Walter Benjamin mira hacia atrás por tres razones:

Primero, porque epistemológicamente es inevitable y necesario mirar hacia atrás, o: el ángel no puede ver adelante y tiene que mirar hacia atrás para poder entender su entorno.

Segundo, porque ontológicamente el futuro no existe, ya que el 'progreso' no es una tendencia de acercamiento a un futuro mejor, sino de alejamiento del paraíso perdido; y porque el tiempo como algo homogéneo que avanza automáticamente, no existe.

Tercero, porque políticamente es necesario mirar hacia atrás, porque no es posible enfrentarse al nacionalsocialismo, si se le entiende como estado de excepción, opuesto a un progreso inevitable. Además mira hacia atrás para salvar a la tradición, de la ocupación por los poderosos, porque las luchas se hacen por los muertos y vencidos de las generaciones anteriores, y no por promesas del futuro.

El aspecto epistemológico

a) Benjamin quiere salvar para la teoría materialista, el conocimiento que ya existía en el idealismo objetivo de Hegel, de que el conocimiento 
es únicamente posible sobre lo pasado. La fantasía humana no tiene la capacidad de inventar lo radicalmente nuevo. Por esta razón no sentimos envidia hacia las generaciones futuras, porque aunque en el caso de que su vida sea mucho mejor que la nuestra, no podríamos imaginarnos esta vida profundamente diferente y mejor y por consiguiente no sentimos ninguna envidia hacia ella. "Una felicidad capaz de despertar envidia en nosotros", dice Benjamin en la segunda tesis, "sólo la hay en el aire que hemos respirado junto con otros humanos, a los que hubiéramos podido dirigirnos; junto con las mujeres que se nos hubiesen podido entregar." (BENJ AMIN, tesis II, 2008, p.36). $\mathrm{Y}$ el texto sigue:

\begin{abstract}
“¿Acaso no nos roza, a nosotros también, una ráfaga del aire que envolvía a los de antes? ¿Acaso en las voces a las que prestamos oído no resuena el eco de otras voces que dejaron de sonar? Acaso las mujeres a las que hoy cortejamos no tienen hermanas que ellas ya no llegaron a conocer?" (BENJAMIN, tesis II, 2008, p. 36 y s.).
\end{abstract}

El conocimiento tiene que basarse necesariamente sobre algo materialmente existente. Tal vez podemos detectar alguna "lógica" de algunos aspectos del desarrollo histórico, pero en última instancia no sabemos lo que realmente va a pasar, y menos aún en un mundo tan irracional - o anárquico cómo diría Marx, de la formación social actual. Lo que sí nos deja restos, aunque sean a veces muy escondidos y difíciles de percibir, es el pasado. Este sí está presente materialmente en nuestra vida cotidiana. Es decir, para ver algo a su alrededor, el ángel de la historia, inevitablemente tiene que ver hacia atrás.

b) Para poder percibir lo más importante de estos restos materiales que nos dejaron las generaciones anteriores, hay que dejar atrás las versiones corrientes que existen de la ciencia de la historia. Se trata de no caer en el error del historicista que usa el procedimiento de compenetración, porque esta se da necesariamente, con los vencedores de la historia. De los vencidos no sabemos nombres, ni conocemos sus rostros, así que un acercamiento emocional a ellos sería por consiguiente más difícil que uno a los vencedores, de los cuales conocemos, por los documentos existentes, detalladamente sus estados de ánimo en distintos momentos de su vida. Pero acercarse a los vencedores de antes, significa a la vez acercarse a los amos de hoy, ya que son los herederos de los vencedores de la historia. ${ }^{10}$ Así que, para que realmente podamos entender hoy las contradicciones existentes, nos hace falta necesariamente una visión crítica y distanciada sobre la 
historia escrita dentro del modelo del historicismo. “[...] el materialista histórico" escribe Benjamin, "mira como tarea suya la de cepillar la historia a contrapelo." (BENJ AMIN, tesis VII, 2008, p. 42 y s.). Hay que mirar, entonces con mucho cuidado y profundidad hacia atrás, para ver las heridas, las cicatrices escondidas debajo de la aparente superficie lisa de la historia. También la izquierda necesita este consejo, ya que en muchas ocasiones cayó en el error de creerle a la historia oficial y sólo ver su diferencia con el pensamiento burgués en declarar que 'a partir de ahora' todo debería cambiar. Esta izquierda no veía que sólo a partir de una visión radicalmente distinta de la historia, sería posible entender mejor la sociedad existente y con esto poder cambiarla desde sus raíces más profundas. ${ }^{11}$

El ángel de la historia mira entonces hacia atrás no solamente porque epistemológicamente no es posible conocer el futuro, sino también porque es necesario conocer verdaderamente el pasado, más allá de la historia oficial, para entender la realidad del presente.

c) Pero la necesidad de conocer el pasado, va más allá de reflexiones sobre la utilidad de este conocimiento para un posible cambio social en el presente. Hay algo que Benjamin no puede nombrar directamente, sino sólo de manera indirecta, pero es tan importante que lo menciona en varias ocasiones a lo largo del corto texto sobre el concepto de la historia. Es algo que tiene gran relevancia para el proyecto de una sociedad diferente, más libre, y a la vez se escapa de reflexiones de utilidad política. Estas últimas son, a su vez, nada más que un reflejo de la reducción que vivimos los humanos en el capitalismo, en la lucha por la subsistencia material. La lógica que surge en esta lucha nos deforma de tal manera, que incluso en el momento de intentar una ruptura con este tipo de organización social, caemos con gran regularidad en el error de repetir su lógica utilitarista y pensar todo en términos de una utilidad política, aunque sea una utilidad para la realización de un plan revolucionario o emancipador. Esta es probablemente la razón porque Walter Benjamin piensa que es necesario que ciertos aspectos de la teología, entren al materialismo histórico para ayudarlo a liberarse de su vinculación demasiado estrecha con el pensamiento y comportamiento burgués, o dicho en términos filosóficos: positivista. Benjamin está convencido de que, a pesar de todo, a cada generación "ha sido conferida una débil fuerza mesiánica a la cual el pasado tiene derecho de dirigir sus reclamos". (BENJ AMIN, tesis II, 2008, p. 37). No es tanto así que tengamos que conocer lo olvidado y saber de los olvidados de la historia para poder mejor cambiar la sociedad, como antes hemos mencionado. Esto sería una interpretación de Benjamin todavía limitada. 
Sino más bien, tenemos la obligación de conocer la historia de los vencidos por ellos mismos. Los vencidos de la historia tienen un derecho sobre nosotros. Estamos en deuda con ellos en el sentido de que no podemos olvidarnos de ellos sin más. El conocimiento de la historia se vuelve así algo mucho más relevante que una herramienta para la futura organización: es un fin en sí mismo. Es tan importante que para tener validez no necesita el dudoso argumento adicional del futuro a construir.

\begin{abstract}
“La imagen verdadera del pasado pasa de largo velozmente [huscht]. El pasado sólo es atrapable como la imagen que refulge, para nunca más volver, en el instante en que se vuelve reconocible. 'La verdad no se nos escapará': esta frase que proviene de Gottfried Keller indica el punto exacto, dentro de la imagen de la historia del historicismo, donde le atina el golpe del materialismo histórico. Porque la imagen verdadera del pasado es una imagen que amenaza con desaparecer con todo presente que no se reconozca aludido en ella." (BENJAMIN, tesis V, 2008, p. 39).
\end{abstract}

Lo que se pierde al no ver hacia atrás, hacia las partes difícilmente visibles del pasado, es, aparte del cumplimiento de un derecho histórico de los vencidos y asesinados de los tiempos anteriores, la posibilidad de reconocernos a nosotros mismos en esta imagen instantánea del pasado $^{12}$. Probablemente sea la única manera de conocernos, es decir, de conocer los fundamentos de nuestra realidad actual, pero este conocer, no hay que entenderlo de manera positivista como una forma más de adquirir algún bien acumulado. Es un conocer fugaz, como el rayo de la tormenta que no puede ser apropiado por nadie y nos deja por un momento ver las montañas durante la noche. Es un acto que tiene su relevancia en sí mismo, no necesita justificación alguna por los efectos más o menos directos que tenga. En esto se distingue la concepción epistemológica, presente en este texto de Benjamin, abismalmente de la concepción de conocimiento de corte positivista, que tenía y tiene mucho peso aún entre aquellos que se definen como marxistas o materialistas históricos. Así como en la teología el acercamiento a la verdad (en este caso, divina) tiene relevancia en sí mismo, lo tiene también para Benjamin. ${ }^{13}$ Por esto, el ángel de la historia no sólo no mira hacia adelante, sino mira necesariamente hacia atrás.

d) Entonces, mirar hacia atrás no es una forma de pensar, de concebirse a sí mismo, de reflexionar sobre la realidad en la cual vivimos, sino es la forma de hacerlo. Pero el asunto todavía es más complicado. No se trata 
solamente de dejar de dirigir la mirada, la atención hacia la idea del futuro o del futuro mejor, hacia la idea del progreso incesante que nos va a liberar casi automáticamente, sino se trata incluso de una forma distinta de mirar, de ver, de reflexionar. Dentro del mismo acto reflexivo, también hay que superar la idea de un progreso inevitable e ininterrumpido. El mismo proceso de reflexión es, al igual que el proceso histórico, algo que no se puede concebir como un acto de acumulación continua de verdades, de realidades entendidas, de conceptos desarrollados o aclarados. El mismo pensamiento está en peligro de perder algo ya encontrado en cada instante. No estamos sobre un punto fijo desde el cual miramos hacia atrás, sino continuamente 'se nos mueve el tapete abajo de los pies' del pensamiento. La fuerza principal que existe en relación a este problema es el olvido. Benjamin comparte esta idea, con otros autores de la Escuela de Frankfurt. ${ }^{14}$ La historia de la filosofía, es en este sentido para Adorno, una historia de olvidos.

Los pensamientos están en continuo movimiento, pero esto no es en sí razón de complacencia, porque este movimiento puede ser justamente la razón por la cual nuestro pensamiento repite eternamente lo mismo y no llega a entender justamente aquellos aspectos de la realidad que nos haría tanta falta entender. Por esto, Walter Benjamin habla de la necesidad de detener los pensamientos ("ihre Stillstellung"). (BENJ AMIN, 1978, p. 702 y s; 2008, tesis XVII, p. 54). El autor explica este procedimiento de la siguiente manera:

\begin{abstract}
"Cuando el pensar se para de golpe en medio de una constelación saturada de tensiones, provoca en ella un Schock que la hace cristalizar como mónada. El materialista histórico aborda un objeto histórico única y solamente allí donde éste se le presenta como mónada. En esta estructura reconoce el signo de una detención mesiánica del acaecer o, dicho de otra manera, de una oportunidad revolucionaria en la lucha por el pasado oprimido. Y la aprovecha para hacer saltar a una determinada época del curso homogéneo de la historia, de igual modo que hacer saltar de su época a una determinada vida o del conjunto de una obra a una obra determinada. El beneficio de este procedimiento reside en que en la obra se halla conservado y superado el conjunto de la obra, en ésta toda la época y en la época el curso entero de la historia. El fruto sustancioso de lo comprendido históricamente tiene en su interior al tiempo como semilla preciosa pero insípida." (BENJAMIN, 2008, tesis XVII, p. 54 y s).
\end{abstract}

Para imaginarse este procedimiento, podemos pensar en la película $\mathrm{SHOAH}$ de Claude Lanzmann. Es un intento excelentemente logrado, de detener el pensamiento y detener el tiempo a lo largo de más de nueve 
horas. En esta obra se cumple cabalmente lo que dice Benjamin en la última cita: "en la obra se (ha) conservado y superado el conjunto de la obra, en ésta toda la época y en la época el curso entero de la historia". Lanzmann dijo en una ocasión que su intento era no dejar solos a los muertos que murieron solos en las cámaras de gas. Nadie va poder revivir estos muertos de una muerte solitaria, pero aunque sea difícil de entender, esta muerte, de cierta manera no ha terminado: "tampoco los muertos estarán a salvo del enemigo si éste vence." (BENJ AMIN, 2008, tesis $\mathrm{VI}, \mathrm{p} .40^{15}$ ). De lo que se trata entonces es, interrumpir esta prolongación de la soledad de estos muertos, arrancarlos de las manos del olvido y abrirles un espacio en nuestra memoria individual y colectiva. Con esto podríamos detener la prolongación de su muerte.

La reacción inmediata, casi preprogramada de la mayoría de los alemanes y de aquellos que quieren compenetrase con ellos sería: 'Pero el nazismo terminó, hace más de medio siglo.' Y sabemos que la frase que sigue en la cita de Benjamin también sería válida: "Y este enemigo no ha cesado de vencer." No es necesario ver Berlusconi en Italia y a sus aliados "pos-" fascistas, o Haider en Austria y la gran aceptación que tiene entre aquellos que se auto conciben como 'conservadores', para saber por qué. En la misma Alemania, incluso en el gobierno actual, podemos ver un sinnúmero de pruebas de que este enemigo de la humanidad, del cual habla Benjamin, no ha cesado de vencer. Esta es la razón principal porque no estamos de acuerdo con la mayoría de las interpretaciones contemporáneas de Walter Benjamin que se hacen dentro y fuera de Alemania, porque la mayoría de sus autores, no comparte este saber y quiere transferir el nacionalsocialismo a un elemento más en el cúmulo de historias que cuenta el historiador de formación historicista.

Entonces, el ángel de la historia mira hacia atrás porque mira hacia allá donde quiso detenerse, pero no lo logró. Quiso detener sus pensamientos sobre un momento de la historia, pero las circunstancias no se lo permitieron, y entonces su mirada es la mirada perdida que trata de alcanzar, con sus ojos, lo que lentamente se está alejando por el horizonte. En esta interpretación, la mirada hacia atrás no es una que ve el pasado, como lo decimos antes, sino una, que trata de ver algo, que hace tan sólo un instante, había logrado detener por un pequeñísimo momento, pero de nuevo la fuerza del olvido se lo arrancó de la mente y de la vista, así que ve hacia atrás, es decir hacia lo que llamamos de manera auto engañosa "el pasado", a donde se le escapó de nuevo a su pensamiento.

Estas reflexiones constituyen una forma de tratar uno de los problemas centrales para el marxismo no dogmático, el marxismo occidental y 
también para la Escuela de Frankfurt: el problema del conocimiento. Para estas corrientes de pensamiento crítico se presentó, en la época del fascismo y nacionalsocialismo, la pregunta de por qué muchos de los miembros anteriores de las organizaciones de masa de la vieja izquierda se sumaron con tanta facilidad a las organizaciones nacionalsocialistas y fascistas. Algunos años antes, en los años veinte, György Lukács se preguntó en Historia y consciencia de clase por qué la revolución, a pesar de estar objetivamente al orden del día, no era percibida de tal manera por las masas explotadas, sobre todo el proletariado, que se había concebido en las versiones ortodoxas del marxismo como el sujeto revolucionario per se. El libro de Lukács, sobre todo el ensayo sobre La cosificación y la consciencia del proletariado, adquirió gran relevancia para el marxismo crítico, justamente por ser el primero que trata esta pregunta de una manera crítica, no perdida en el progresismo y la confianza ingenua en el proletariado.

En parte, el texto Sobre el concepto de historia de Benjamin, es una respuesta sui generis a esta pregunta. Tiene en común con los otros autores del marxismo no dogmático la idea, de que la forma de actuar del proletariado y de sus organizaciones de masa no se pueden explicar únicamente a partir de las relaciones económicas, así como se pensaba en ocasiones en el marxismo dogmático. En el marxismo crítico, la Teoría crítica, se parte de la idea de que hay que analizar los problemas de conocimiento para poder entender la ausencia de revoluciones socialistas en los años veinte en Europa, a pesar de que objetivamente sus condiciones estaban dadas según las teorías clásicas de izquierda. Es decir, el marxismo occidental, a partir del cual se desarrolla también la Teoría crítica de la Escuela de Frankfurt, se concentra en estos años en la crítica a la ideología. El texto de Benjamin se encuentra inscrito en este contexto. Comparte con los otros autores de esta corriente, la idea de que la ideología dominante está también en las cabezas de los oprimidos incluyendo el proletariado, y no solamente por la manipulación por parte de las instancias ideológicas de las clases dominantes, sino a partir de la realidad material existente. Las mismas contradicciones muy profundas de la forma social existente hacen imposible concebirla racionalmente y provocan ellas mismas una falsa percepción. De cierta manera, se puede decir que la forma de reproducción capitalista tiene la gran ventaja, en comparación con otras formaciones que existían en épocas anteriores, de tener la virtud de zafarse de la comprensión de si misma por parte de sus propios sujetos. Por esto Benjamin coincide con los otros pensadores del marxismo occidental en la percepción de que estando adentro de esta sociedad, no 
es posible entenderla, pero en una sociedad más libre sí sería probablemente posible:

\begin{abstract}
"Aunque, por supuesto, sólo a la humanidad redimida le concierne enteramente su pasado. Lo que quiere decir: sólo a la humanidad redimida se le ha vuelto citable su pasado en cada uno de sus momentos." (BENJAMIN, 2008, tesis III, p. 37).
\end{abstract}

Lukács ve la razón principal para este hecho en la cosificación, es decir en la circunstancia de que relaciones entre humanos adquieren la forma de relaciones entre cosas, sobre todo las mercancías y se queda invisible su aspecto social. Las relaciones sociales se cosifican materialmente, porque en el capitalismo los sujetos tienen cada vez menos influencia sobre los productos hechos por ellos y sobre la relación social construida por ellos históricamente, y en consecuencia se cosifica la conciencia. Dicho en otras palabras: lo que está en movimiento, las relaciones sociales siempre cuestionables, se nos presentan como algo incuestionable, sin movimiento, eterno. Lukács intenta hacer brincar precisamente esta aparente calma de, como dirían después los nacionalsocialistas, los mil años.

El enfoque de Benjamin es distinto, aunque parte de la misma inquietud, o dicho de un modo más exacto: va más allá de lo planteado por Lukács. György Lukács percibe con gran talento, el hecho de que el movimiento histórico se le escapó a sus propios actores, así que ellos sólo se concibieron a sí mismos como los que cumplen, sin posibilidad de decisión propia o influencia activa, un papel predeterminado. La crítica de Lukács se dirige en contra de la misma tendencia teórica y política que la de Benjamin: la socialdemocracia, es decir la izquierda reformista (hoy también llamada centro izquierda), sobre todo la socialdemocracia alemana y su determinismo histórico. Quería interrumpir esta idea de no poder actuar por cuenta propia fuera de las tendencias ya dadas, con la idea del movimiento: movimiento contra estancamiento cosificador. Benjamin va más allá de esta concepción heredada del pensamiento dialéctico de Hegel. Sabe de la importancia del movimiento en la realidad y en el pensamiento, pero también sabe que no hay que quedarse ahí, rescata la importancia de la interrupción del movimiento, que no es lo mismo que el no-movimiento.

La razón de esto es el progresismo a criticar, que cimentó con su fijación en el movimiento (por supuesto como uno predeterminado), toda posibilidad de una intervención activa por parte de los sujetos de la historia. Benjamin rescata esta posibilidad con la detención del movimiento. 
e) Hay una última forma más de concebir a nivel epistemológico, por qué el ángel de la historia mira hacia atrás. El ángel no mira solamente hacia atrás, para entender lo que está fuera de él, como lo hemos analizado en las interpretaciones anteriores, sino también para entenderse a sí mismo. No lo decimos en el sentido de entenderse a sí mismo a partir de conocer la propia historia, el contexto de la propia vida, sino en el sentido realmente de verse a sí mismo, mirando hacia atrás, o dicho de otro modo: confrontando el ayer con el hoy de manera directa, interrumpiendo el continuum histórico. Esto puede parecer a la primera vista demasiado especulativo o casi místico, pero no lo es, y lo es además mucho menos que la ideología del "progreso como norma histórica". (BENJ AMIN, 2008, tesis VIII, p. 43).

Benjamin nos hace aprehender algo sumamente complejo del funcionamiento de la memoria en este aspecto de su texto Sobre el concepto de historia. Sabe que se necesita una confrontación de dos momentos históricos en uno solo, para poder realmente entender, para realmente poder activar la capacidad de la memoria. A esto se refiere, entre otras cosas, cuando dice: "un secreto compromiso de encuentro [Verabredung] está entonces vigente entre las generaciones del pasado y la nuestra" (BENJ AMIN, 2008, tesis II, p. 37) y cuando escribe:

\begin{abstract}
"Articular históricamente el pasado no significa conocerlo 'tal como verdaderamente fue'. Significa apoderarse de un recuerdo tal como éste relumbra en un instante de peligro. De lo que se trata para el materialismo histórico es de atrapar una imagen del pasado tal como ésta se le enfoca de repente al sujeto histórico en el instante del peligro." (BENJ AMIN, 2008, tesis VI, p. $40^{16}$ )
\end{abstract}

En el momento del peligro vemos las imágenes de los recuerdos no como algo pasado, como algo que está a distancia, separado por el tiempo de nosotros hoy, sino, lo vemos como algo presente en este momento. Nos confrontamos de manera inmediata con estas imágenes y nos vemos a nosotros mismos en ellas. Este es el único momento en el cual lo que llamamos memoria es realmente capaz de hacernos entender algo nuevo. En otros actos de 'memoria', no hacemos otra cosa que usar imágenes ya suavizadas y preparadas para fundamentar todo lo que de por sí estamos pensando e imaginándonos. Pero estos no son actos de memoria, sino una citación superficial y sin seriedad de imágenes que ya están domesticadas por el signo que les dimos en el contexto de nuestras explicaciones.

Habría que entrar de pleno en el problema de la conflictiva relación entre imagen y signo que existe en el pensamiento ilustrado, para poder 
explicar a fondo esta problemática ${ }^{17}$, lo que aquí no es posible. Pero es central tener presente que en la sociedad represiva, explotadora, es decir no libre, nuestras formas de percibir tampoco son libres y en última instancia están siempre guiadas por el prehistórico miedo de desaparecer, es decir, son guiadas por los impulsos de la autoconservación. Esto provoca que signo e imagen estén en un continuo conflicto, y la imagen, en el momento de ser absorbida por el signo, pierde por completo su fuerza y su verdad. De esto sabe Benjamin y también por esto busca la interrupción de estos procesos aparentemente normales de ver la historia. Sólo cuando la imagen histórica tiene su pleno derecho, puede tener un efecto iluminador sobre nuestra consciencia y sólo puede tener este derecho pleno, si se confronta el momento histórico pasado de manera inmediata con nosotros. Por esto, el ángel de la historia se ve a sí mismo cuando ve hacia atrás. Él mismo está ahí, en el pasado, o dicho de otra manera, el momento específico del pasado está presente frente a él mismo en el mismo momento.

En un comentario sobre la nueva película de Claude Lanzmann, Sobibor, 14 de octubre 1943, 16 horas, podemos ver cómo Lanzmann sabe de esto cuando realiza esta película:

\begin{abstract}
"Hay una secuencia imposible de olvidar en la cual Lanzmann utiliza un recurso sencillo para recrear el inimaginable terror del pasado. Por un largo momento, la cámara enfoca repetidamente a una enorme manada de gansos blancos que están graznando. Avanzan tambaleándose en círculo, estirando los cuellos, desconcertados, chocando con pánico unos con otros, sin saber a donde ir. Después de un rato, el significado se aclara. Para camuflar, ante los demás en el campo, los gritos de las mujeres aterrorizadas que eran conducidas a la cámara de gas, los nazis mantenían una manada de gansos que soltaban en momentos cruciales. Esta escena es el eco terrible de esos momentos." 18
\end{abstract}

En SHOAH, Lanzmann hace regresar por un momento a un entrevistado a su antigua profesión de peluquero, sólo para entrevistarlo en esta situación, mientras corta el pelo a un señor. Lanzmann le pregunta sobre los recuerdos de su estancia en un campo de exterminio nacionalsocialista. Le hace recordar y contar, cómo cortó el pelo de las mujeres, instantes antes de que entraran a la cámara de gas, a veces incluso dentro de la misma, antes de que cerraran las puertas. Le hace recordar esto, justo cuando repite el acto de cortar el pelo a un humano, y él cuenta cómo fue, cuando otro estilista a su lado tenía que cortar el pelo a mujeres muy cercanas y quiso morir con ellas. La escena es de las que más se nos grabaron en la mente, porque Lanzmann logró 
perfectamente interrumpir el continuum de la historia y confrontar un momento del pasado de manera inmediata, fuera del control de la interpretación de signos, con el sobreviviente hoy. Esta interrupción del continuum de la historia, abarca incluso al espectador, que pierde por un instante, aunque sea mínimo, la sensación del tiempo como homogéneo e infrenable, y se le abre un espacio para ver algo en el pasado como si fuera hoy, en este momento. O dicho de otro modo: ve de repente el sobreviviente en la cámara de gas, cortando el pelo a las mujeres instantes antes de cerrar las puertas, ve como él se ve ahí y ve de repente algo que nunca había logrado ver o percibir por otros métodos.

La memoria que tan fácilmente se deja corromper, en esta sociedad corrompida por su forma económica y social, encuentra una fisura en la máquina sin piedad que llamamos tiempo. Y en esta pequeñísima fisura, que sólo ven los que no cierran súbitamente los ojos ante el horror que se esconde en lo que llamamos nuestro pasado, se abre por instantes, instantes que son una eternidad, un espacio de libertad que permite a la memoria emerger lo que había estado hundido y condenado al olvido. ${ }^{19}$

El aspecto ontológico

a) El ángel de la historia no sólo mira hacia atrás, sino todo su cuerpo está orientado hacía atrás. Todo lo que menciona la novena tesis de Walter Benjamin sobre el ángel de la historia está atrás, del "adelante" no se habla. Lo único que sabemos del "adelante", es que ahí va el ángel en contra de su voluntad y sin poder controlarse, empujado por una fuerza a la cual quisiera resistir sin lograrlo. Esta fuerza, tempestad o huracán, este Sturm como dice Benjamin, es lo que llamamos el progreso.

Pero ese Sturm del progreso no está orientado hacia el futuro, como se dice por lo regular, sino que viene del paraíso, nos está alejando continuamente de él. Es decir, el futuro no existe, sólo lo podemos imaginar como el potencial resultado del alejamiento del paraíso, de la incapacidad de detenernos. Pero ontológica o materialmente, el futuro es inexistente. Es únicamente el resultado imaginativo de nuestra fantasía y de nuestra incapacidad de ver con calma el presente. La idea del futuro es el resultado de la negación al presente que se vive plenamente, es el presente interrumpido. La fijación en la idea del futuro es a la vez la negación al derecho de las generaciones pasadas sobre nuestra débil fuerza mesiánica, porque la fijación en el futuro es inseparable del olvido del pasado. Justo en el momento de no realizarse este derecho de las generaciones anteriores, se corta la banda que nos une con ellas y caemos en un abismo. A este abismo obscuro lo 
llamamos "futuro" en el momento de caernos hacia él, así como pueblos de otros tiempos dieron nombres a los fenómenos naturales inexplicables, para superar el miedo que lo inexplicable provoca. El continuo intento de hablar sobre, planear e imaginar el futuro, no es entonces otra cosa que el intento de nombrar lo innombrable para someterlo a nuestra lógica, que a su vez es nuestra arma tan amada para superar el miedo hacia todo lo desconocido. ${ }^{20}$

Pero el futuro no es solamente innombrable por no ser perceptible o entendible, así como se explicó en la parte epistemológica, sino porque no existe. La infinidad de discusiones dentro del positivismo sobre el problema de la falsificación (Popper), vienen justamente de ahí. El positivismo que busca las verdades seguras sobre la realidad existente, cae por lo general en la trampa de pensar que puede hacer afirmaciones sobre el futuro, a partir de análisis hechos sobre el pasado. Pero a la vez, sus mejores representantes se dan cuenta que el futuro "todavía" (como dirían), no existe. Entonces, proyectan el momento de la verdad - falsedad de una teoría a uno posterior, con la construcción de la falsificación de una teoría. Esta construcción no es otra cosa que el fallido intento de hacer un brinco hacia el futuro, pero reinterpretado desde un otro hoy. Se quiere reconstruir el hoy como el "futuro del ayer", y en esta construcción superar la contradicción más elemental del positivismo: su creencia ingenua en los hechos, que siempre tienen que ser hechos comprobables, comprobación que sólo puede ser realizada después que pasaron; y a la vez, su ímpetu incansable de dar conocimientos que hacen planeable el mundo existente, lo que deberá ser orientado hacia lo que llamamos el futuro.

Benjamin, quien quiere superar la debilidad teórica de la izquierda, que en gran parte se debe a la presencia relevante que tiene el pensamiento positivista en ella, detecta con mucha claridad que sólo criticando el concepto ingenuo del futuro y con esto, el concepto ingenuo del tiempo como vacío, lineal y homogéneo, puede hacer caer el edificio teórico del positivismo que tanto impresiona a los que no ven el suelo blando de la fe en el dios cronos sobre el cual está construido.

b) Pero: ¿qué es la fe en el dios cronos?

En el pasaje que probablemente es el más radical de todo este texto, Benjamin escribe:

“La idea de un progreso del género humano en la historia es
inseparable de la representación de su movimiento [Fortgang,
S.G.] como un avanzar por un tiempo homogéneo y vacío. La
crítica de esta representación del movimiento histórico debe 
constituir el fundamento de la crítica de la idea de progreso en general." (BENJ AMI N, 2008, tesis XIII, p. 50 y s.).

No es casual que muchos de los intérpretes de Benjamin, dejan a un lado en sus comentarios sobre el texto, este pasaje, sin el cual la radicalidad de las tesis sobre el concepto de historia no se puede percibir ni lejanamente. Esta radicalidad rebasa por mucho la alcanzada en la teoría social y filosofía contemporánea, tanto, que parece una locura intentar retomarla o por lo menos defenderla. Como ya expusimos en las notas preliminares, la teoría social y la filosofía, nunca llegaron a retomar lo establecido por la teoría de la relatividad de Einstein. Nunca se entendió en estos ámbitos de la ciencia, que también el tiempo al igual que la energía, la masa y la extensión física (distancia), no son, como se pensaba antes de la teoría de la relatividad, absoluto, sino dependen cada uno de los otros factores. Para la teoría social y la filosofía, el aprendizaje debería ser que el concepción del tiempo como algo absoluto, como punto seguro de referencia, es la respuesta ideológica de una sociedad que es caótica, llena de contradicciones antagónicas y estructuras profundamente irracionales. Mientras la sociedad en sí no pueda dar la seguridad necesaria a sus miembros de ser una forma que les ayude a vivir en vez de dificultarlo, esta sociedad necesitará establecer estructuras fuera de ella, supuestamente dadas por las leyes naturales, que reemplacen la organización racional que la misma sociedad burguesa no es capaz de ofrecer a sus miembros. ${ }^{21}$ Es básicamente el tiempo el que sirve como medidor entre los humanos para hacer equiparables sus productos, que desde un principio son inequiparables. El hecho de que este factor, que se declara objetivo y absoluto precisamente por ser una categoría absoluta en las ciencias naturales, se quede intacto a pesar de ser superado como tal en la las ciencias naturales, expresa con toda claridad su carácter de construcción ideológica.

Pero el pensamiento positivista, tan presente en las interpretaciones socialdemócratas y estalinistas del marxismo en la época de Walter Benjamin, no puede retomar los nuevos descubrimientos de las ciencias naturales, no a pesar, sino justamente por su fijación en el método de ellas. Su relación con las ciencias naturales es por definición una relación dogmática y no crítica, así que ni siquiera le interesan los nuevos descubrimientos, porque más que dar las seguridades que los pensadores dogmáticos siempre buscan, provocan dudas, que son el escenario de horror para ellos.

Walter Benjamin se percata con gran claridad de esta contradicción básica en las teorías e ideologías dominantes desde su tiempo hasta 
hoy. Su crítica al concepto dominante de tiempo puede aparecer mística, ideológica o sumamente teológica. De cierta manera la teología le ayuda a superar las concepciones dogmáticas de la ideología positivista dominante, pero lo que busca es un concepto estrictamente materialista de tiempo, uno que no cae en el error de declarar una de las necesidades de la forma de reproducción capitalista como un hecho objetivamente existente, tal como lo hace el positivismo.

Es decir, el ángel de la historia está orientado hacia atrás, porque es la única orientación posible en términos ontológicos. El adelante como algo existente en dirección hacia el futuro, que con el supuestamente indetenible paso del tiempo se alcanzará pronto, no tiene ninguna manera racional de ser concebido. En este sentido, el adelante no existe, es la nada, que en cada momento es declarado existente por las necesidades de la forma de reproducción capitalista, por la dinámica de la autoconservación, que en esta sociedad es totalitaria. ${ }^{22}$ Dicho en otras palabras: el ángel de la historia está orientado hacia atrás, porque hacia el "adelante" sólo se pueden orientar los creyentes en el dios cronos, así como sólo los creyentes en ciertos dioses pueden orientar su vida hacia su fe en una futura entrada al cielo.

Paradójicamente, es justamente la teología la que ayuda a Walter Benjamin a superar la creencia positivista en el dios cronos y con esto fundar una teoría radicalmente materialista. Al final es la teología la que Walter Benjamin pone a su servicio, para superar los restos teológicos en las versiones positivistas del marxismo socialdemócrata y estalinista, es decir, para superar el marxismo dogmático. En última instancia, es la vieja creencia en la salvación dentro de un espacio fuera del tiempo y fuera del mundo, la que está presente en el progresismo y en la creencia fanática en el dios cronos. El mesianismo de Benjamin no es otra cosa que el intento de dejar atrás de una vez por todas los restos del mesianismo en el pensamiento que se auto concibe como ilustrado. Así como Horkheimer y Adorno tratan de salvar el proyecto de la ilustración precisamente por la vía de su crítica radical, Walter Benjamin intenta superar definitivamente los restos mitológicos y teológicos en el pensamiento ilustrado (en su forma del positivismo), por la vía de poner a su servicio una última vez, pero esta vez conscientemente, la teología. ${ }^{23}$

Horkheimer y Adorno plantean en los Elementos del antisemitismo ${ }^{24}$ que el acto de conocimiento contiene siempre un elemento de proyección, que al ser negado al estilo positivista, refuerza sus efectos por hacerse incontrolable. Ellos distinguen entonces entre proyección bajo control, la proyección controlada por la razón consciente de que necesita la proyección para poder aprehender el mundo, y proyección 
falsa, que es la proyección negada y por esto, imposible de ser controlada. De una manera parecida se puede distinguir entre elementos teológicos controlados, porque la teoría es consciente de la ayuda que necesita de ellos, y elementos teológicos falsos, que son aquellos que son negados por la teoría y por lo mismo sus efectos irracionales se multiplican y se salen de todo control racional. El primer caso sería el de Benjamin, y el segundo el del marxismo socialdemócrata y de las otras versiones del positivismo.

c) La orientación hacia atrás del ángel de la historia, implica también que el ángel avanza sin poder controlar adecuadamente sus pasos, avanza ciegamente, e incluso en contra de su voluntad.

“El ángel quisiera detenerse [...]. Pero un huracán sopla desde el paraíso y se arremolina en sus alas, y es tan fuerte que el ángel ya no puede plegarlas. Este huracán lo arrastra irresistiblemente hacia el futuro, al cual vuelve las espaldas". (BENJ AMI N, 2008, tesis IX, p. 44).

El movimiento que realiza el ángel es entonces un movimiento enajenado, uno que realiza sin poderlo controlar. Así es la situación del mundo actual en su condición provocada por la forma de producción capitalista: avanzamos indeteniblemente, no solamente por el progreso tecnológico, sino también por la necesidad aparentemente eterna de luchar por la sobrevivencia. Es decir, no solamente no podemos ver hacia adonde nos dirigimos, sino en el momento mismo, nuestro actuar es un actuar torpe, en cada instante podemos caernos. El no poder ver a donde vamos implica también el no poder controlar nuestro cuerpo. Así como el ángel no puede cerrar sus alas para poderse detener y hacer los movimientos que quisiera hacer, así somos nosotros en esta sociedad: fuerzas exteriores nos impiden movernos como quisiéramos, trabajamos cada vez más, pero sin decidir qué producimos, cómo usarlo y quién lo puede consumir. Corremos con la corriente, pero no así como pensaba la socialdemocracia, que el avanzar automático de la historia nos acerca cada vez más hacia el socialismo y el puro hecho de levantar los pies, es decir, de trabajar, nos acerca a la sociedad sin clases. ${ }^{25}$ Más bien, es al revés: lo que llamamos progreso, es justamente uno de los factores que nos impiden controlar nuestros pasos, nuestro cuerpo, entendido no solo como el cuerpo individual sino también como el colectivo, es decir la sociedad. Es el progreso técnico el que nos 'ayuda' a avanzar sin saber adonde y sin poder controlar los pasos.

Esto es justamente a lo qué se refiere Marx en su famoso texto sobre el fetichismo de la mercancía y su secreto en el primero tomo de El 
Capital, y que György Lukács y el marxismo occidental en general retoman en el concepto de ideología como consciencia necesariamente falsa. Por el puro hecho de actuar, de hacer algo, de caminar en la imagen del ángel de la historia, pensamos que somos activos y pensamos que esta actividad nos constituye como seres libres e independientes. Por esto podemos festejar, a veces tan frenéticamente, la forma de reproducción capitalista. A la vez, y esto es el punto clave del secreto de la estabilidad ideológica de la formación social reinante, sabemos, intuimos, percibimos que es todo lo contrario a la verdad social e histórica: nuestros pasos son pasos definidos por dinámicas ajenas a nuestra voluntad, nuestro avanzar en lo tecnológico y productivo es bajo las condiciones existentes un retroceder en lo social, en el sentido de que con cada nuevo producto que hicimos, dimos un arma más a las manos de nuestros explotadores y opresores. O dicho en las palabras de Karl Marx: con cada nuevo producto aumentamos el capital en las manos de los dueños de los medios de producción y aportamos algo a que se abra cada vez más el abismo entre los que venden su fuerza de trabajo como su única propiedad y los que acumulan más y más medios de producción.

Es esta contradicción entre avanzar y retroceder, como procesos simultáneos, la que se expresa de una manera singular en la imagen del ángel de la historia. Avanza, pero mirando hacia atrás y contra su voluntad, ya que quisiera detenerse. Es decir, desde la perspectiva del lugar en el cual hubiera querido detenerse, se aleja, retrocede.

Entonces, el ángel de la historia que camina de espaldas, es la sociedad burguesa con su formación de producción capitalista: con cada paso del avance del progreso tecnológico, industrial y organizativo (en el sentido de una organización fuera del control de la sociedad, solamente en manos de algunos, es decir una organización instrumental), se aleja de sus viejas promesas de liberté, égalité, fraternité. Con cada paso cimienta más y más profundamente las estructuras de explotación, represión y control generalizado.

d) Pero: ¿Por qué el huracán sopla desde el paraíso?

“Pero un huracán sopla desde el paraíso y se arremolina en sus alas, y es tan fuerte que el ángel ya no puede plegarlas. Este huracán lo arrastra irresistiblemente hacia el futuro, al cual vuelve las espaldas, mientras el cúmulo de ruinas crece ante él hasta el cielo. Este huracán es lo que nosotros llamamos progreso." (BENJ AMIN, 2008, tesis IX, p. 44 y s.) 
El huracán sopla del paraíso, porque nos aleja de él, como decimos en las interpretaciones anteriores. Pero a la vez esta imagen incluye otro aspecto, igualmente importante. Este otro aspecto abre de nuevo el campo de tensión que existe en el pensamiento dialéctico de Benjamin, educado en Marx. Este huracán, este viento que llamamos progreso, sopla del paraíso no sólo porque de esta dirección tiene que llegar para podernos alejar de este paraíso, sino también porque es una fuerza del paraíso mismo, que surge en él, tiene su origen en él. La exclusión del paraíso no era el resultado del acto de comer la fruta de la sabiduría, sino los dos eran uno y el mismo hecho. O dicho de otra manera: la exclusión del paraíso era el resultado del acto de comer la fruta del conocimiento y al mismo momento y en el mismo sentido, el deseo y la necesidad de comer esta fruta era el resultado de ser excluido del paraíso. El progreso tecnológico es desde el primero momento contradictorio: razón de nuestra infelicidad así como expresión y método principal de nuestros intentos por superarla.

Sería una interpretación sumamente limitada de Walter Benjamin el no ver esta contradicción. Benjamin no es simple y sencillamente un crítico del progreso tecnológico, sino es un crítico del progreso tecnológico en las condiciones existentes, es decir hoy en día, en las condiciones de la forma de reproducción capitalista. En este punto, su posición es también fundada en Marx, pero de nuevo con el intento de radicalizarlo y de superar los momentos en los cuales Marx cae de repente en simplismos históricos. ${ }^{26}$ En el capítulo sobre maquinaria y gran industria del primer tomo de El Capital, Marx no se cansa en hacer la distinción entre la maquinaria en sí y la maquinaria aplicada de manera capitalista ${ }^{27}$. En su texto La obra de arte en la época de su reproductibilidad técnica (BENJAMIN, 2003.) Benjamin retoma este motivo y lo aplica a las nuevas técnicas artísticas de su época, sobre todo el cine. Este ensayo, está escrito en la misma fase que el texto sobre el concepto de historia, es decir en la fase marxista de Walter Benjamin. El espíritu del texto está muy claro, Benjamin trata de salvar el cine de sus críticos conservadores y también de sus críticos de izquierda, subrayando la capacidad técnica del cine de aplicar los últimos inventos, es decir de no cerrarse al progreso de las fuerzas productivas, pero a la vez está claramente consciente, que estas nuevas posibilidades no se pueden aplicar de manera adecuada bajo las condiciones existentes de la forma económica capitalista.

Si se olvida esta dialéctica del progreso tecnológico, que a su vez es parte de lo que Horkheimer y Adorno conciben como la dialéctica de la ilustración, no se puede captar en última instancia nada de la radicalidad del pensamiento de Benjamin. El huracán del progreso viene del 
paraíso, tiene su origen ahí, es en sí algo con ciertas fuerzas paradisíacas, y a la vez es lo que nos aleja del paraíso, lo que nos impide, por lo menos en las relaciones dominantes, actuar libremente y detenernos ahí donde sería necesario.

La inseguridad que provoca esta frase sobre el origen del huracán en el texto de Benjamin, viene de la contradicción inherente a esta imagen. El huracán impide al ángel de la historia ayudar a los destrozados, lo arrastra, pero viene del paraíso. Las explicaciones que dimos al inicio de la parte ontológica, solamente son correctas si se entienden en el contexto de esta última, que es su contraparte. La fuerza de este viento no es el progreso como lo entendió ingenuamente la socialdemocracia y también el estalinismo. Pero tampoco es la mera fuerza destructiva, que nos aleja del paraíso perdido al que sólo habría que regresar, renegando a las liberaciones que - a pesar de todo - ha logrado la humanidad, así como lo dirían ciertos conservadores y por supuesto todos los grupos de los más diversos fanatismos nacionalistas, racistas y religiosos que tanto auge tienen hoy en día.

La fuerza ideológica del nacionalsocialismo era justamente la de jugar con esta contradicción y moverse con agilidad en ella. Por esto, la mera fijación al aspecto reaccionario de la extrema derecha, como lo hizo y hace hasta hoy la socialdemocracia, no ayuda nada a entenderlo. A la vez hay que ver, y en esto insiste mucho Benjamin en los aspectos políticos del texto Sobre el concepto de historia, la cara modernizadora, orientada hacia el progreso tecnológico y organizativo que el nacionalsocialismo tenía, y movimientos contemporáneos que tienen tendencias parecidas. ${ }^{28}$

\section{El aspecto político}

a) El ángel de la historia mira hacia atrás, porque la auténtica acción revolucionaria es así: no espera el momento en el cual 'las condiciones objetivas están dadas' para tener este o el otro efecto, no espera hasta que haya el público (Ilamado 'base de masas') que garantice el aplauso frenético, no espera hasta que haya la seguridad de entrar en los anales de la historia posterior como héroes y además como héroe ganador. La acción revolucionaria es más bien, la que siempre tiene su momento, la que no quiere asegurase un lugar en el mundo futuro, sea por su éxito, sea por las futuras generaciones que estarán agradecidas hasta en la quinta de ellas. La acción revolucionaria, tal como ha sido hasta hoy, y como la concibe Benjamin, es una interrupción del tiempo vacío que avanza ciega y homogéneamente. En este avanzar ciego y homogéneo, no hay ningún momento preestablecido para la revolución, no hay un lugar en el teatro de la historia con una placa que diga: apartado para la 
revolución. La revolución no es un paso más en este avanzar aparentemente automático del tiempo, sino es algo fuera de esta normalidad totalitaria que es el tiempo en su concepción hoy en día dominante. Las revoluciones no son la consecuencia lógica de momentos o fases históricas anteriores, que sólo se distinguen por su contenido, sino se distinguen también radicalmente por su forma: las revoluciones se salen de la lógica del tiempo lineal, homogéneo y orientado hacia el futuro. Son los no momentos de la historia, son aquellos que no caben en la lógica histórica y que la interrumpen.

Pero las revoluciones no están por esto fuera de la historia, sólo están fuera de su lógica orientada hacia el futuro, fuera de su avanzar a pesar de todo, con la fijación en la imposibilidad de no avanzar, es decir de salirse de todo y cuestionar radicalmente todo. Las revoluciones son el momento, en el cual algunos humanos deciden no dejarse impresionar por la supuesta imposibilidad de parar aquella maquinaria gigantesca de la cual todos formamos parte - queramos o no. Son el momento en el cual podríamos recordar instantáneamente la libertad humana, perdida en el tiempo que avanza como un reloj suizo y nunca nos deja ver, ni pensar, ni dudar ni un momento, porque the show must go on.

Entonces, la relación que tienen las revoluciones con la historia, es necesariamente una relación con el pasado. Al salirse de la lógica de la fijación hacia el futuro, no les queda otra opción que orientarse hacia el pasado, y a la vez, restauran la posibilidad de detenerse, de no dejarse llevar por los "Sachzwänge" ("necesidades objetivas"), de no creer el mito de la imposibilidad de detenerse aunque sea un momento, de no caer en la trampa eterna de la supuesta necesidad de tantos 'puntos finales' que los poderosos exigen, para hacernos olvidar los muertos, los heridos, los humillados y los responsables de todo esto.

Por esto el ángel de la historia mira hacia atrás: es la revolución que sólo puede relacionarse con el pasado y que a la vez retomó la libertad de detenerse y dar la mano a los oprimidos, a los muertos, a los olvidados de todos los tiempos.

b) Pero: ¿qué es una revolución? Las revoluciones no sólo son aquellos acontecimientos que después se registran en la historia como tales porque de una o otra manera lograron imponer algo y construir un nuevo sistema social. Las revoluciones, o los actos revolucionarios, son cualquier intento logrado de interrumpir la maquinaria que funciona aparentemente de manera indetenible con el ritmo sin piedad de los relojes. Por esto Benjamin habla también de "una oportunidad revolucionaria en la lucha por el pasado oprimido". (BENJ AMIN, 2008, tesis XVII, p. 54 y s.). 
La idea 'grande' de las revoluciones, tiende a alejarnos del real entendimiento de las revoluciones, se idealizan posteriormente solamente aquellas que lograron imponerse y se reconstruye después este éxito como algo dado desde su principio. Esto tiene un doble efecto: por un lado, que esta idea mitificada de las revoluciones nos aleje de la posibilidad de hacer nosotros mismos una, ya que no podemos imaginarnos, que justamente somos nosotros a quienes nos 'toca' hacer uno de estos grandes acontecimientos que cambian supuestamente el mundo para siempre. Intuimos que nuestra fuerza mesianica, como dice Benjamin es débil $y$, como se nos enseñó, en la idea mitificada de las revoluciones, que sus actores son héroes con una gran fuerza mesiánica, entonces no nos vemos capaces de competir con ellos. Por otro lado, la mistificación de las revoluciones niega sus aspectos obscuros, criticables, y los absolutiza a la vez como algo insuperable. ¿Si los grandes revolucionarios de antes no podían realizar estas revoluciones ejemplares sin actos que hasta hoy nos congelan la sangre en las venas; entonces, ¿de qué manera nosotros, que supuestamente somos mucho menos predestinados a ser revolucionarios, podríamos atrevernos a criticarlos 0 incluso imaginarnos, hacer una revolución distinta, no tan repugnante? ${ }^{29}$

Un acto revolucionario sería entonces aquel que logra interrumpir, aunque sea por un instante, el continuum de la historia, parar un momento el tiempo, el avanzar de las cosas que se nos presentan como independientes de nosotros. O dicho en el lenguaje de Marx en sus momentos de más fuerza crítica: los actos revolucionarios serían entonces aquellos que logren diluir instantáneamente el fetichismo de nuestros productos que se nos presentan como fuerzas ajenas a nosotros. La mirada hacia atrás del ángel de la historia es entonces a la vez una mirada tímida, dirigida hacia abajo, hacia lo pequeño, casi invisible, porque sólo así reconoce aquellos actos revolucionarios que desde la perspectiva actual son pequeños y más cerca del suelo que del cielo.

c) En referencia al Marx en sus momentos de un ingenuo optimismo histórico, así como lo conocemos por ejemplo del Manifiesto, Benjamin anota en uno de sus esbozos relacionados con las tesis sobre el concepto de historia:

\footnotetext{
"Marx dice que las revoluciones son las locomotoras de la historia mundial. Pero tal vez esto es completamente distinto. Tal vez las revoluciones son el momento en el cual el genero humano, que viaja en este tren, acciona el freno de emergencia." (BENJ AMIN, 1980, p. 1232) ${ }^{30}$
} 
Para entender esta frase en su verdadero sentido y peso hay que ver los años en los cuales Benjamin escribió este texto y también los años que siguieron inmediatamente después, así como todo este texto de Walter Benjamin no se puede entender ni remotamente, si no se conoce las historia del nazismo y del fascismo y menos aún si no se conoce la historia de la destrucción de los judíos europeos. ${ }^{31}$

La imagen del freno de emergencia que debiera detener el tren, es más que una imagen que el filósofo usa para hacer entender sus ideas al público interesado. Es la realidad misma. Cuando el autor de estas líneas comentó la frase de Benjamin arriba citadas a Claude Lanzmann, quien ha realizado la mejor película de todos los tiempos, la mejor película sobre la destrucción de los judíos europeos y quién no solamente ha estudiado, sino hablado con una parte importante de sus pocos testigos oculares directos sobrevivientes, Lanzmann contestó espontáneamente en el sentido de que esto se refiere a la Shoah. ${ }^{32} \mathrm{El}$ freno de emergencia que el acto revolucionario podría accionar, sería entonces, según la interpretación de este intelectual, quien con su película SHOAH ha creado una obra artística que se acerca de una manera increíble a la concepción filosófica expresada en el texto a discutir de Benjamin, no cualquier freno de emergencia en cualquier tren, sino más bien, el freno de emergencia en un tren que se dirigía a Auschwitz, Sobibor, Treblinka u otro de los campos de extermino nacionalsocialistas.

Pero estos trenes no tenían freno de emergencia. Avanzaron puntualmente ${ }^{33}$ hacia su destino. La destrucción de los judíos europeos no se salió del horario de la historia, sino fue justamente el resultado de nuestra incapacidad de interrumpirlo:

“La tradición de los oprimidos nos enseña que el 'estado de excepción' en que ahora vivimos, es en verdad la regla. El concepto de historia al que lleguemos debe resultar coherente con ello. Promover el verdadero estado de excepción se nos presentará entonces como tarea nuestra, lo que mejorará nuestra posición en la lucha contra el fascismo. La oportunidad que éste tiene está, en parte no insignificante, en que sus adversarios lo enfrentan en nombre del progreso como norma histórica. El asombro ante el hecho de que las cosas que vivimos sean 'aun' posibles en el siglo veinte no tiene nada de filosófico. No está al comienzo de ningún conocimiento, a no ser el de que la idea de la historia de la cual proviene ya no puede sostenerse." (BENJ AMIN, 2008, tesis VIII (completa), p. 43). 
Si alguien hubiese logrado detener los trenes a Auschwitz, Treblinka, Sobibor, su acto hubiera sido revolucionario. Tal vez parar un solo tren lleno de gente en el camino al exterminio inmediato, hubiera sido más revolucionario que los actos de Robespierre y Danton juntos. Probablemente pocos hablarían hoy de este acto, pero esto no cambia nada del asunto. En su nueva película "Sobibor, 14 de octubre de 1943, 16 horas", Claude Lanzmann hace recordar justamente un acto de esta índole, del cual muy pocos saben y menos aún hablan: la insurrección en el campo de exterminio nacionalsocialista Sobibor el día catorce de octubre de mil novecientos cuarenta y tres que comenzó a las dieciséis horas. Poco después de esta insurrección, este campo fue cerrado por los nacionalsocialistas para borrar toda memoria de que los presos judíos lograron interrumpir esta maquinaria de la muerte. Entonces, la insurrección logró, además de salvar la vida a unas sesenta personas destinadas por los nacionalsocialistas a la muerte, detener el funcionamiento de este campo de exterminio de manera definitiva.

Por esto el ángel de la historia mira hacia atrás, porque estos actos revolucionarios son dirigidos a parar la maquinaria, detener el tiempo, interrumpir el progreso que en su ceguera y vaciedad es el aliado 'natural' de los opresores y genocidas.

d) Pero estos actos revolucionarios no son para festejarlos. El ángel de la historia no puede levantar su mirada, que tiene dirigida hacia los muertos, y voltearse con un gesto de heroísmo y acto festivo hacia el sol que se levanta. Estos actos revolucionarios no son para festejarse, no solamente por lo obvio de su debilidad, ya que sólo lograron detener una pequeña parte de la maquinaria, lejos de pararla en su totalidad, sino también, porque son actos revolucionarios negativos. Su único fin es, parar el tren que va directo a la muerte. Pero no arrancan nuevos trenes a lugares llenos de felicidad.

Cuando Walter Benjamin habla de la necesidad de "cepillar la historia a contrapelo" (BENJAMIN, 2008, tesis VII, p. 43), se refiere también a esto: para entender el concepto de revolución que él introduce, hay que cepillar también la historia de las revoluciones a contrapelo. El que sólo ve las revoluciones a partir de las grandes batallas ganadas, no entiende en este falso heroísmo nada de la verdadera historia de las rebeliones y actos revolucionarios. Es probablemente justo esta falsa concepción heroizante de las revoluciones, la que nos aleja hoy tanto de su posibilidad, necesidad y realidad.

La mirada hacia atrás, angustiada y llena de tristeza del ángel de la historia, es entonces a la vez fuente de esperanza: si incluso el ángel de la historia no tiene los ojos llenos de seguridad de vencer, de avanzar 
firmemente, entonces, ¿porque nosotros vamos a pedir tanta seguridad, tantas condiciones objetivas dadas para atrevernos a interrumpir el continuum? El antihéroe de Brecht que hace posible el entendimiento de que nosotros mismos podríamos también hacer algo aquí abajo, está presente en el ángel de la historia, que está orientado hacia atrás. ${ }^{34}$

e) Si Benjamin habla entonces, de "una débil fuerza mesiánica" (BENJAMIN, 2008, tesis II, p. 37), no solamente retoma ciertos momentos de la teología, sino critica a la vez las fantasías de omnipotencia que acompañan por lo regular la afirmación de que ahora, todavía no es el momento para demostrar al mundo lo que desde un principio podríamos hacer con él. La arrogancia, la incapacidad de ver los propios límites, está inseparablemente vinculada con la subestimación de la propia capacidad de intervención histórica. 'Seríamos aquellos que liberan el mundo de una vez para todas de todos sus males, si sólo el progreso, el curso automático de la historia nos llevara al momento correcto, si sólo las condiciones objetivas estuvieran dadas', esto es el lema de aquellos políticos que unen en una sola persona, en un sólo movimiento "la fe ciega ... en el progreso, la confianza en su "base de masas'" con "su servil inserción en un aparato incontrolable". ${ }^{35}$ Y por esto, los políticos de la llamada izquierda reformista tienen que mandar a reprimir de vez en vez los movimientos de rebelión espontáneos que no pueden controlar. Piensan que éstos interrumpen su avanzar hacia el momento glorioso, que no entienden que hay que marchar por las instituciones para un día - un día levantarse, demostrar su fuerza siempre escondida con "su servil inserción en un aparato incontrolable", para salvar el mundo de tal manera que hasta el Mesías de las tradiciones religiosas se quedaría pálido de envidia.

Pero la fuerza mesiánica que tenemos, cada generación, cada uno y cada una, es esto: débil. Es pequeña, tal vez igual de fea que el enano que tiene que esconderse que Benjamin menciona en la primera tesis, pero: es el secreto de cada acción, aunque sea la más pequeña, que se realiza en la historia contra la opresión, la explotación, la exclusión, la persecución y el olvido de sus víctimas.

El mesianismo de Benjamin está orientado hacia atrás por esto: para distinguirse del mesianismo arrogante y lleno de miedo a la vez, de los auto declarados salvadores potenciales del mundo. Benjamin sabe muy bien que los muertos no van a revivir por una política distinta o por el recuerdo que les brindemos. Pero sabe que su muerte no es definitiva, es decir, no es un proceso ya acabado: "tampoco los muertos estarán a salvo del enemigo si éste vence. $Y$ este enemigo no ha cesado de 
vencer." (BENJ AMIN, 2008, tesis VI, p. 40). Los nuevos vencedores, que muchas veces se auto declaran los redentores de los muertos anteriores, hacen morir de nuevo a los muertos al burlarse de sus esperanzas no cumplidas, de sus intentos fallidos de interrumpir el curso ciego de la historia. En el mismo momento en que estos políticos organizan el olvido de los muertos, que a su vez es el olvido de sus esperanzas que hoy tampoco se están cumpliendo, declaran que pronto todo será mejor y que todas nuestras fuerzas deben ser orientadas hacia adelante, para cuando venga el momento (si viene) estar preparados, y en un sólo acto, superar todo lo anterior.

Nuestra fuerza mesianica es débil, porque lo que en el mejor de los casos podremos lograr: la sociedad sin clases, como dice Benjamin citando a Marx, no es la solución gloriosa y definitiva de todo el sufrimiento y la garantía para todas las generaciones futuras de una mejor vida. No, la sociedad sin clases no es otra cosa que el momento en que logremos interrumpir el progreso de la historia. ${ }^{36}$ En comparación con las promesas de los políticos de la izquierda reformista de la época de Benjamin, es algo realmente pequeño. Pero en comparación con lo que ellos hicieron realmente y considerando lo que significó el nacionalsocialismo y el fascismo para la humanidad, hubiera sido algo infinitamente grande.

f) Orientarse hacia atrás, también podría entenderse como la apología del tradicionalismo. Pero lo que propone Benjamin, que también está presente en la imagen del ángel de la historia que mira hacia atrás, es "el intento de arrancar la tradición de manos del conformismo, que está siempre a punto de someterla." (BENJ AMIN, 2008, tesis VI, p. 40). No sólo se trata de la "tradición de los oprimidos", (BENJ AMÍ N, 2008, tesis VIII, p. 43) sino de la tradición en su totalidad. La izquierda ha cometido a lo largo de su historia repetidamente el error, de identificar tradición con tradicionalismo. Este error está directamente relacionado con la idea de un progreso en la historia de la cual la izquierda sería un aliado 'natural'. Todo lo que quedó atrás es, en esta lógica, lo que hay que superar, de lo cual hay que distanciarse. Benjamin, quien critica esta concepción y además la concepción de un tiempo lineal que avanza así como lo hacen creer los relojes que sólo se paran cuando uno olvida darles cuerda o cambiarles la batería, no acepta esta identificación de tradición y tradicionalismo, en la cual la izquierda y la derecha se parecen más de lo que estarían dispuestos a admitir.

La izquierda en sus versiones positivistas (la reformista y la estalinista) parte, al igual que las tendencias burguesas, de la idea de que la tradición esté siempre del lado de los conservadores y derechistas. Si 
ciertos grupos de la izquierda tratan de incluir en sus programas, aspectos de la tradición local, lo harán no con la idea de una radicalización de su posición política, sino como un acercamiento táctico a posiciones de la derecha o de los conservadores.

Es impensable dentro de una ideología progresista y economicista, que en la tradición existente haya siempre una herencia rebelde y subversiva, no sólo en la "tradición de los oprimidos", sino también en las tradiciones que trataron de garantizar una buena vida y desarrollar las capacidades y necesidades humanas, más allá de las necesidades económicas inmediatas. Es inimaginable para la izquierda positivista al igual que para los conservadores, que justamente lo que frena el progreso tecnológico, organizativo y económico, podría estar a favor de un proyecto revolucionario. Por esto la izquierda casi siempre tenía y tiene graves problemas, cuando se trata de entender o incluso apoyar peticiones de grupos minoritarios ${ }^{37}$, ya que presentan por lo general una vuelta demás en el cauce dentro del cual corre el río del progreso nacional. Son innumerables los ejemplos, pero sólo hay que recordarse de los problemas que tenían los sandinistas en Nicaragua en aceptar las peticiones de los grupos indígenas, de los cuales varios acabaron entonces como aliados de la contra, así como el caso de México. Aquí fue sólo a partir de la aparición de los neozapatistas que surgió una todavía limitada - consciencia dentro de la izquierda de que la lucha por una sociedad menos represiva y menos explotadora, podría ser a la vez la lucha por el reconocimiento de las tradiciones que no son subsumibles bajo el concepto clásico del 'Mexicano' o de la 'Mexicana', así como se estableció en un afán emancipador en los últimos dos siglos.

Este grupo es tal vez uno de los primeros que a su vez trata de unir abiertamente estos dos aspectos: por un lado, la defensa de la tradición, que está en peligro de ser aplastada por la tendencia de la forma de reproducción capitalista de destruir las diferencias que no caben en su declaración de igualdad de todas las mercancías, y por tanto de todos los que están dispuestos a reducirse a meros productores de ellas. Por otro lado, este grupo trata de retomar los viejos ideales emancipatorios de una sociedad más justa, más igualitaria, etcétera.

Las eternas discusiones que se pueden observar desde hace unos años sobre la cuestión de si hay que dar preferencia a las peticiones de igualdad 0 a las de diferencia, sólo son posibles por esta falsa contradicción que se construye en el pensamiento dominante entre tradición y emancipación. Todas las afirmaciones, hoy en día ya de moda, de estar en contra del progresismo y economicismo, son en vano, si no se llega hasta la cuestión de la tradición como algo que hay que 
"arrancar... de manos del conformismo". (BENJ AMIN, 2008, tesis VI, p. 40).

Retomar la tradición de una manera no folklorista, podría ser lo que Walter Benjamin llama el "salto de tigre al pasado" (BENJAMIN, 2008, tesis XIV, p. 52), pero este salto no significa alejarse de la posibilidad de una sociedad radicalmente distinta a la existente y sus estructuras destructivas y represoras, sino "ese salto dialéctico [...] es la revolución como la comprendía Marx." (BENJAMIN, 2008, tesis XIV, p. 52). Ser revolucionario implicaría entonces la capacidad de recordarse, de ver y aprender de las generaciones pasadas, de sus experiencias y tradiciones. La simple fijación en las supuestas 'modernizaciones' nos cierra, por el contrario, el camino a este salto del tigre. Las recetas de la izquierda reformista y estalinista en las excolonias de superar primero los restos de sociedades tradicionales, es decir, asemejarse a las sociedades del centro, como requisito previo para poder entrar al proyecto de una sociedad radicalmente menos repugnante, se basan en esta falsa concepción del papel de las tradiciones. Los neozapatistas son tal vez el grupo que ve con más claridad la necesidad de este salto del tigre hacia el pasado y no es casual que lo hacen desde el rincón mas retirado de México, aparentemente desde el lugar más alejado de esta otra sociedad menos represora. El ángel de la historia mira entonces hacia atrás para ver allá, muy lejos, en las tradiciones perdidas, el punto a donde el tigre podría saltar e interrumpir el continuum de la historia. La teoría de los cuatro ethe de la modernidad capitalista de Bolívar Echeverría, y sobre todo sus análisis del ethos barroco como uno moderno y no premoderno, podría ser uno de los pocos intentos teóricos que hoy en día lograron retomar este análisis de Walter Benjamin que por lo general está - a pesar de ser citado con frecuencia marginalizado en el actual debate socio filosófico. La concepción del ethos barroco como uno que contiene una "combinación conflictiva de conservadurismo e inconformidad"38, podría ser justamente una de las claves para entender el tipo de modernidad que existe en México, no como una retrasada, sino una diferente y tal vez en ciertos aspectos hasta más interesante para el proyecto de una sociedad menos represiva, explotadora y repugnante que la existente, que las modernidades del primer mundo que la izquierda partidaria y 'oficial' (lo que quede de ella), al igual que los conservadores, ingenuamente quieren copiar.

g) El ángel de la historia mira hacia atrás, porque si no, le podrían asaltar por la espalda. 
El ángel de la historia, si le entendemos como representante de la humanidad en su propia historia, está en continuo peligro. Muchos de los políticos de la izquierda reformista pensaron, que sólo hay que correr hacia adelante, para construir un mundo más libre, pero se les olvidó lo que cualquier vaquero del oeste sabe: hay que cuidarse la espalda. También la historia tiene una espalda, tiene sus reversos, sus lados obscuros. En la ideología progresista no cabía la idea de que estos lados obscuros podrían tener alguna relevancia. Y este error de la izquierda reformista de la época de Walter Benjamin se repite hoy en día.

Se pensaba, que las ideologías que se conciben como retrógradas: el racismo, el antisemitismo, el belicismo, el chauvinismo, serían superadas por el mero progreso histórico. El puro hecho de que los relojes y los calendarios avanzaran, así como que las tecnologías se renovaran y desarrollaran cada vez más, les parecía garantía suficiente de que estas ideologías y sus respectivas prácticas no eran más que un resto de los malos viejos tiempos. La izquierda reformista hasta suele llamar las formas más repugnantes de explotación, por ejemplo en ciertas zonas del llamado tercer mundo, 'formas feudales'. Implícitamente había la idea de que el capitalismo y la sociedad burguesa son por sí un avance histórico. No vieron lo que la Escuela de Frankfurt llama la dialéctica de la ilustración. No vieron, que las bestialidades cometidas en esta sociedad no eran restos de algo feo anterior, que se irían en el momento que la sociedad burguesa estuviera presente en todo el mundo y en cada rincón, así como en cada momento, sino algo que es intrínsecamente una parte de esta sociedad.

Este error se podía cometer por razones políticas, pero también por una interpretación limitada y muy selectiva de Marx. Este autor es contradictorio en este punto, pero la izquierda positivista, es decir la socialdemocracia y los estalinistas, no querían ver esta contradicción en este filósofo, ya que les interesaba más la utilidad política de su teoría. Pero una teoría demasiado complicada y contradictoria no sirve para movilizar multitudes y menos aún sirve para indoctrinarlos por los jefes y demagogos de los partidos.

Querían unir las multitudes detrás de ellos con los métodos que conocían de la guerra: con gritos que convencían a los guerreros en cada momento, que van a vencer y que la muerte será de los otros, y la gloria, la victoria y la recompensa para ellos mismos. La ideología del progreso necesario e inevitable, del socialismo como consecuencia lógica del curso predestinado de la historia, en última instancia no era otra cosa que estos gritos de guerra. Y esto mismo era una de las razones, porque tan fácilmente una parte muy grande de los votantes del partido socialdemócrata y del partido comunista de Alemania y de muchos otros 
países de Europa, cambiaron de parecer para votar en favor de los partidos de extrema derecha en el momento que empezó su auge. Querían estar con los vencedores tal como sus líderes políticos de la izquierda reformista y estalinista les habían enseñado por años.

Pero: nunca aprendieron a cuidarse la espalda. Pensaron que detrás de ellos, todo lo que concibieron como retrógrada, del pasado, se caería por si sólo. Por esto había ante el nacionalsocialismo (y hay hasta hoy), tanto "asombro ante el hecho de que las cosas que vivimos sean 'aún' posibles en el siglo veinte" (BENJAMIN, 2008, tesis VIII, p. 43). Pero, este asombro "no tiene nada de filosófico. No está al comienzo de ningún conocimiento, a no ser el de que la idea de la historia de la cual proviene ya no puede sostenerse." (BENJAMIN, 2008, tesis VIII, p. 43). No pensaron que 'detrás' de ellos podría crecer algo que no se diluye por si sólo o por el mero avanzar del tiempo o de la historia.

Su fijación en los gritos de guerra que eran los eternos discursos del futuro a ganar, de las batallas que hay que hacer por un mejor futuro de los hijos (léase: para ser festejado posteriormente por ellos y todas las generaciones que siguen, así como se festeja hasta hoy la revolución francesa, la independencia de Estados Unidos, etcétera.), se fundaron sobre todo en el miedo, o como dirían los autores de la Escuela de Frankfurt: en la incapacidad de salirse de la lógica de la lucha por la supervivencia, a pesar de que económicamente ya podríamos hacernos independiente de esta lógica desde los años veinte del siglo veinte. Estos gritos de guerra eran la ideología del progresismo, y en última instancia, también lo es, la ciega creencia en el tiempo como algo idéntico al avanzar de los relojes, como algo homogéneo, lineal, ininterrumpido y vacío. Estas ideologías y estas prácticas políticas, se basan en la falta de otra dinámica que podría hacernos actuar.

Por esto Walter Benjamin insiste en el aspecto mesiánico, siempre con la idea de que a nosotros "nos ha sido conferida una débil fuerza mesiánica" (BENJAMIN, 2008, tesis II, p. 37). La falta de esta consciencia lleva con cierta necesidad a los mencionados gritos de guerra del progresismo, historicismo y de la fe en el dios cronos. Benjamin sabe del momento no planeable, no previsible de cada revolución. Es además una de las mayores fuerzas de los oprimidos, tener mucho menos la necesidad de planear que la de los opresores que sólo logran oprimir el mundo con cierta planeación. Por eso los oprimidos tienen cierta libertad instantánea al momento de empezar una rebelión o una revolución. Es esta fuerza que la izquierda de índole positivista quita a los oprimidos al querer integrar y hacer previsible todo, es decir también en las rebeliones y revoluciones, dentro de su concepto vacío de historia y del tiempo como lineal y homogéneo. 
Pero entonces: ¿de donde puede venir la dinámica revolucionaria, si no es desde los gritos de guerra que son la fijación en el futuro y la idea de nadar "a favor de la corriente"? ${ }^{39}$ La tesis XII que probablemente es, en términos políticos, una de las más fuertes, dice al respecto:

\begin{abstract}
“E1 sujeto del conocimiento histórico es la clase oprimida misma, cuando combate. En Marx aparece como la última clase esclavizada, como la clase vengadora que lleva a su fin la obra de la liberación en nombre de tantas generaciones de vencidos. Esta conciencia, que por corto tiempo volvió a tener vigencia con el movimiento Spartacus, ha sido siempre desagradable para la socialdemocracia. En el curso de treinta años ha logrado borrar casi por completo el nombre de un Blanqui, cuyo timbre metálico hizo temblar al siglo pasado. Se ha contentado con asignar a la clase trabajadora el papel de redentora de las generaciones futuras, cortando así el nervio de su mejor fuerza. En esta escuela, la clase desaprendió lo mismo el odio que la voluntad de sacrificio. Pues ambos se nutren de la imagen de los antepasados esclavizados y no del ideal de los descendientes liberados." (BENJ AMIN, 2008, tesis XII (completa), p 48 y s.).
\end{abstract}

La única dinámica que realmente puede llevarnos a luchar, no como guerreros o como mercenarios, quienes en cualquier momento pueden cambiar de bando si el otro parece estar más fuerte, es: la "imagen de los antepasados esclavizados". Es una imagen de algo real, algo que realmente pasó, mientras que lo que propone la socialdemocracia es algo meramente pensado, ideal: el "ideal de los descendientes liberados". En el momento de que este ideal, o la posibilidad de realizarse en un mediano plazo, se pone en duda, la lucha acaba por sí sola, así como pasó en más de una ocasión en la historia, con el ejemplo inolvidable del papel que jugó la socialdemocracia alemana al inicio de la época del nacionalsocialismo, cuando sus diputados en el parlamento alemán aprobaron el 17 de mayo de 1933 - una semana después de las quemas públicas de libros- la declaración oficial del gobierno nacionalsocialista sobre su política exterior. El 19 de junio del mismo año, el comité ejecutivo del Partido Socialdemócrata Alemán (SPD) destituyó a los miembros judíos de dicho comité; tres días después el partido fue de todos modos prohibido.

Por esto el ángel de la historia mira hacia atrás: porque sólo del recuerdo de las represiones y humillaciones del pasado, así como de las viejas esperanzas y de uno que otro intento revolucionario, se puede sacar una fuerza política que no se deje someter tan fácilmente como le pasó con increíble regularidad a la izquierda reformista. Dicho de otro modo: mira hacia atrás porque el pasado no pasó, todas las bestialidades del pasado que creemos haber superado, pueden renacer 
en cualquier momento de tal manera y tal magnitud que no lo podemos imaginar. La fuerza que tenemos en la lucha política, no será lo que nos lleve con seguridad hacia nuevas tierras llenas de felicidad, sino una que intente, a partir del recuerdo, evitar que se 'repita' (y cada vez podría ser peor que la anterior, porque las técnicas no sólo avanzan para una aplicación productiva y liberadora, sino también para una aplicación destructiva y opresora) lo que pasó y que solamente parece haber desaparecido o haber sido superado.

h) El ángel de la historia mira hacia atrás por la prohibición de la imagen.

La referencia abierta que hace Walter Benjamin en la última de sus tesis, a la religión judía nos abre el paso a la última interpretación de la mirada retroperspectiva del ángel de la historia. "[...] a los judíos les estaba prohibido investigar el futuro" (BENJAMIN, 2008, tesis B, p. 59), pero además les es prohibido hacerse una imagen de dios, ni siquiera deben pronunciar esta palabra como tal. La distancia entre la imperfección de los seres humanos y su realidad, es decir, su sociedad en relación a la perfección divina, es para los creyentes tan grande que cada imagen que un ser humano se hace de este dios es por si misma una blasfemia, y la manera más segura de alejarse de la verdad divina. Así pasa con la imagen de un futuro mejor, un futuro sin opresión, sin clases, sin explotación, un futuro más libre. Incluso los adjetivos aquí usados están lejos de describirlo. Porque también ellos provienen de una historia demasiado larga de falsificación, manipulación y supuestas realizaciones mediocres o auto destructivas. El futuro realmente diferente, el que merece ese nombre, no sólo no se puede ver, como decimos en la parte epistemológica y tampoco no sólo no existe, como decimos en la parte ontológica, sino, políticamente el futuro como proyecto es la manera más perfecta de impedir su realización.

Sólo en la prohibición absoluta de mencionarlo, dios puede existir para un judío creyente. De la misma manera, sólo volteando la atención con firmeza hacia el lado opuesto, la acción política sería capaz de encontrar lo que radicalmente rompe con las herencias destructivas y nefastas, de crear lo que era anhelado desde siempre por los oprimidos y aniquilados de siempre.

Pero este voltear la atención hacia el lado opuesto no se refiere solamente a ver hacia el pasado en vez de fijarse en el futuro invisible, inexistente, y problemático cuando se busca frenéticamente. El lado opuesto es también la no política, lo que está fuera de lo que por lo regular concebimos como tal. Sólo en las esferas que a los profesionales de la política les parece que son las más alejadas de ella, podría 
encontrarse la chispa de la esperanza revolucionaria que tanto buscó Walter Benjamin.

\section{Referencias Bibliograficas}

BENJ AMIN, W. "Sobre el concepto de historia". In: BENJ AMIN, W. Tesis sobre la historia y otros fragmentos. Trad. e introd. Bolívar Echeverría. México, Itaca/Universidad Autónoma de la Ciudad de México, 2008, p. 31-59.

"Über den Begriff der Geschichte." In: BENJAMIN, W. Gesammelte Schriften, v. 1, n. 2, p. 693-704, 2a ed. Frankfurt am Main 1978.

\section{. La obra de arte en la época de su reproductibilidad}

técnica. Trad. Andrés E. Weikert. México, Itaca, 2003. 127p.

. Anmerkungen zu den Thesen über den Begriff der Geschichte.

In: W. B. Gesammelte Schriften, ed. de Rolf Tiedemann y Hermann

Schweppenhäuser, tomo I.3. Frankfurt am Main: Suhrkamp, 1980.

\section{Endereço para correspondência}

Stefan Gandler

Universidad Autónoma de Querétaro, Facultad de Ciencias Políticas y Sociales, Cerro de las campanas s/n,76010, Querétaro, Qro., Mexico

Endereço eletrônico: stefan.gandler@gmail.com

Recebido em: 30/05/2010

Aceito para publicação em: 9/07/2010

Acompanhamento do processo editorial: J orge Coelho Soares e Ariane P. Ewald

\section{Notas}

* Professor e orientador do Programa de mestrado e doutorado em Filosofía da Universidad Nacional Autónoma de México, Facultad de Filosofía y Letras.

${ }^{1}$ Redactado en 1940. Incluido en: Horkheimer, Max und Adorno, Theodor W. (Eds.). Walter Benjamin zum Gedächtnis. Los Angeles, Institut für Sozialforschung, 1942, 166p., p. 1-6. [mimeógrafo]. Primera publicación impresa, como traducción al francés, realizada por Pierre Missac y autorizada por Max Horkheimer y Theodor W. Adorno, con el título: "Sur le concept d'histoire". En: Les Temps Modernes, Paris, julio-diciembre 1947, v. 3, n. 22-27, p. 624-634. Primera edición impresa del original en alemán en: Die Neue Rundschau, 1950, v. 61, n. 4, p. 560-570. En lo siguiente citamos según las siguientes ediciones, en español: Walter Benjamin, "Sobre el concepto de historia". En: W.B., Tesis sobre la historia y otros fragmentos. Trad. e introd. Bolívar Echeverría. México, Itaca/Universidad Autónoma de la Ciudad de México, 2008, 118p., p. 31-59; y en alemán: Walter Benjamin, "Über den Begriff der Geschichte." En: W.B., Gesammelte Schriften, v. I, n. 2, p. 693-704, 2a ed., Frankfurt am Main 1978.

${ }^{2}$ Aquí no es el espacio para desarrollar más esta questión. Para reflexiones más elaboradas sobbre este probela véase: Stefan Gandler, Marxismo crítico en México, Adolfo Sánchez Vázquez y Bolívar Echeverría. Prólogo Michael Löwy. México, D.F.: 
Stefan Gandler

Para un concepto de no lineal de Historia

Fondo de Cultura Económica/Facultad de Filosofía y Letras, Universidad Nacional Autónoma de México/Universidad Autónoma de Querétaro, 2007, 621p. 1a reimpresión: 2008.

${ }^{3}$ Véase: "La idea de un progreso del género humano en la historia es inseparable de la representación de su movimiento [Fortgang, S.G.] como un avanzar por un tiempo homogéneo y vacío. La crítica de esta representación del movimiento histórico debe constituir el fundamento de la crítica de la idea de progreso en general." (Walter Benjamin, "Sobre el concepto de historia", loc. cit., tesis XIII, p. 50 y s.; Walter Benjamin, "Über den Begriff der Geschichte", loc. cit., tesis XIII, p. 701. Nota: Bolívar Echeverría traduce "Fortgang" con "movimiento", aunque la palabra tiene en alemán una clara connotación de una movimiento dirigido 'hacia adelante', sentido que se pierde parcialmente con la palabra española propuesta por el destacado filósofo traductor.)

${ }^{4}$ Para justificar este procedimiento se usa la clásica figura del pensamiento burgués en la época del capitalismo tardío, es decir, del capitalismo en su fase de dar patadas de ahogado: En vez de entender a Hegel y su dialéctica con la idea de la transformación de cambios cuantitativos en cambios cualitativos, se trata de reducir un cambio cualitativo a un cambio cuantitativo: se argumenta, que los descubrimientos de la teoría de la relatividad sobre la relatividad del tiempo, sólo son aplicables en términos de "muy grandes velocidades" o "muy grandes distancias" que supuestamente no existen en la vida cotidiana de los seres humanos. Se reduce de nuevo algo cualitativo a algo cuantitativo para poder excluir las consecuencias de muy largo alcance de la crítica al concepto de tiempo realizada por Einstein para la formación social existente. ${ }^{5}$ El último residuo de esta guerra de muy larga duración entre distintos calendarios por el predominio a escala mundial, era el debate - a veces grotesco - sobre si el nuevo milenio empezó el 1 de enero del año 2000 o del año 2001. Casi en ninguna de las distintas aportaciones a esta discusión, se hizo referencia a la base histórica de esta confusión que está, por una parte, justamente en la historia conflictiva de los sistemas calendarios y por otra parte, justamente en la historicidad de los sistemas de contar el tiempo: en el momento que se inventó el calendario gregoriano en Europa todavía no existía el concepto del cero. Por consiguiente no se podía contar en "año cero", que llevó al hecho hasta hoy existente de que en la línea de tiempo que establece el calendario que usamos con tanto convencimiento de su objetividad, se rompe con lo establecido en la matemática moderna, de tal manera que - contando desde los números negativos - después del menos uno (-1) se brinca directamente al uno (1), sin contar el cero (0). En la disputa sobre el verdadero inicio del nuevo milenio casi todos los participantes partieron de la objetividad del calendario hoy en día dominante y sólo se disputaron sobre su interpretación correcta, sin darse cuenta que el mismo calendario es en términos de matemática moderna incorrecto. Esto es una expresión más de la incapacidad de nuestra sociedad por reflexionar críticamente sobre su concepto de tiempo, y darse cuenta que este concepto como existe hoy en día sólo tiene su justificación en la forma social a la que corresponde y no se debe a ninguna objetividad fuera de esta forma social.

${ }^{6}$ Nos referimos aquí al concepto del "ethos realista" de Bolívar Echeverría. Este ethos es para Echeverría, aquel que se auto concibe como 'realista'. En este ethos se percibe la sociedad existente con una gran ingenuidad, lo que se basa en la ilusión de la noexistencia de contradicciones básicas en esta sociedad. En este 'realismo', la realidad no está presente tal cual en su consciencia, como piensa que así sea, sino más bien, es un realismo normativo, para decirlo de alguna manera. Parte de la idea de que las normas y reglas de juego existentes, están plenamente cumplidos en la realidad, cualquier transgresión la puede concebir solamente como excepción y es incapaz de 
concebirla como expresión de una contradicción sistemática. En este sentido el ethos realista es aquel que no tiene la menor capacidad de concebir una posible diferencia entre el concepto de tiempo dominante hoy en día y la realidad temporal misma. El ethos barroco en cambio, que tiene cierta presencia limitada en América Latina, es el que sabe de las contradicciones inherentes a la sociedad existente y podría entonces incluir más que el realista, la capacidad de percibir el carácter ideológico del concepto de tiempo hoy en día reinante. Lo que la mayoría de los alemanes perciben entonces en México como impuntualidad, que a su vez interpretan como una forma menos racional y menos modernizada de actuar, podría ser más bien una forma más inteligente de percibir las contradicciones del concepto actual de tiempo. (Véase por ejemplo: Bolívar Echeverría, “Modernidad y capitalismo (15 Tesis)". En: Bolívar Echeverría, Las ilusiones de la modernidad. México, Universidad Nacional Autónoma de México/El Equilibrista, 1995. 200p.).

${ }^{7}$ Benjamin compró esta obra en 1921.

Véase por ejemplo: "[La confianza en sí, la valentía, el humor, la astucia y la incondicionalidad, S.G.] van a poner en cuestión, siempre de nuevo, todos los triunfos que alguna vez favorecieron a los dominadores. Como las flores vuelven su corola hacia el sol, así también todo lo que ha sido, en virtud de un heliotropismo de estirpe secreta, tiende a dirigirse hacia ese sol que está por salir en el cielo de la historia." (Ibid., tesis IV, p. 38 y s.) Este "sol que está por salir en el cielo de la historia" es sin lugar a dudas una sociedad menos represiva y exploradora que la existente.

"Véase la tesis XI, donde Benjamin habla de la "concepción positivista" de los teóricos socialdemócratas (BENJ AMIN, tesis XI, 2008, p. 47).

${ }^{10}$ "Y quienes dominan en cada caso son los herederos de todos aquellos que vencieron alguna vez." (BENJ AMIN., tesis VII, 2008, p. 41 y s.).

${ }^{11}$ Sobran ejemplos para esto, aquí nos limitamos sólo a dos: la cada vez más grande referencia afirmativa de los estalinistas a la "patria grande" de Rusia, y con esto la completa pérdida de una visión crítica sobre la tradición imperialista que había en este país hacia las otras naciones dentro de la nueva Unión Soviética. Esta falta de visión crítica, este situarse tan fácilmente en la tradición de los vencedores anteriores, era la base de una política sumamente represiva hacia las naciones no rusas de la URSS. El otro ejemplo sería, la mayoría de la izquierda mexicana, que por muchos años se negó a ver la terrible herencia del racismo colonial dentro de México y con esto, auto limitó su posibilidad de criticar y superar el racismo anti indígena hasta hoy existente.

${ }^{12}$ Véase los textos de Shoshana Felman que no por casualidad trabaja sobre Benjamin y a la vez escribió, según el juicio del propio Claude Lanzmann, el mejor texto sobre su película SHOAH, concentrándose justamente en el problema del testimonio (y con esto del rescate de la memoria en tiempos de su destrucción sistemática) hoy en día (véase: Shoshana Felman, "A I'age du témoinage: SHOAH de Claude Lanzmann" en Bernard Cuau, et al., Au sujet de Shoah. Le film de Claude Lanzmann. París, Belin, 1990, p. 55-145).

${ }^{13}$ No es por demás afirmarlo de nuevo: muchas de las versiones "pequeñas" de la teología, se olvidaron de este aspecto central en varias religiones y redujeron cada vez más el acercamiento a la verdad divina, a un medio para llegar a otro fin (como por ejemplo, pagar "deudas" adquiridas con dios por algún pecado, o para vencer algún enemigo). El problema de varias versiones de la teología es justamente, que se orientan de manera esclavizada a la lógica impuesta por la lucha por la sobrevivencia, es decir, al modelo positivista. La crítica que hace Benjamin a la interpretación socialdemócrata del marxismo histórico, caería entonces también sobre ellos. Dicho en otras palabras, no es "la teología" que retoma Benjamin para radicalizar el 
materialismo histórico, sino una versión de ella que es radical y opuesta a la mayoría de las instituciones y prácticas religiosas hoy en día existentes.

${ }^{14}$ Nos referimos a los que hoy en día, en una confusión filosófica creciente, se llaman en ocasiones "la primera generación", en una distinción innecesaria de la llamada segunda, tercera, y seguramente en unos años más: la cuarta y quinta. Esta distinción es innecesaria, ya que son tendencias teóricas tan lejanas y en muchas ocasiones opuestas en aspectos claves a la Escuela de Frankfurt, que no es necesario diferenciarlos por "generaciones", porque ya están distinguidos por ser proyectos filosóficos aparte.

${ }^{15}$ El pasaje completo es: “Encender en el pasado la chispa de la esperanza es un don que sólo se encuentra en aquel historiador que está compenetrado con esto: tampoco los muertos estarán a salvo del enemigo si éste vence. Y este enemigo no ha cesado de vencer."

${ }^{16}$ Véase también en la tesis V: “La imagen verdadera del pasado pasa de largo velozmente [huscht]. El pasado sólo es atrapable como la imagen que refulge, para nunca más volver, en el instante en que se vuelve reconocible." (BENJAMIN, 2008, tesis V, p. 39.)

${ }^{17}$ Véase sobre esto: Max Horkheimer y Theodor W. Adorno: Dialéctica de la ilustración. Fragmentos filosóficos. Trad. Juan José Sánchez. Madrid 1994: Ed. Trotta, capítulo: “Concepto de ilustración", p. 59-95.

${ }^{18}$ Peter Lennon, "Ghosts of Sobibor". En: The Guardian, Manchester, 27 de julio de 2001. Original: "There is one unforgettable sequence in which Lanzmann uses a simple device to recreate the demented terror of the past. For a long moment, the camera pans repeatedly over a huge gaggle of squawking white geese. They stagger about raucously, necks stretching, bewildered, bumping against each other in panic, not knowing which way to go. After a while, the significance dawns. To camouflage the screams of the terrified women being led to the gas chamber from others in the camp, the Nazis kept a gaggle of geese which they set loose at crucial moments. This scene is the dreadful echo of those moments."

${ }^{19}$ No solamente los crímenes de los nacionalsocialistas están condenados al olvido, sino también los actos de resistencia, sobre todo cuando fueron realizados por judíos. Los nacionalsocialistas hicieron todo lo posible para que no quedara ningún recuerdo de la insurrección exitosa en el campo de exterminio Sobibor el 14 de octubre de 1943 a las 16 horas, en la cual lograron escapar 300 personas. Por esto se supo sólo años después algo más de esta insurrección. Los poderosos siempre temen, no solamente el recuerdo de sus actos destructivos, sino también el recuerdo de la posibilidad de que personas mucho menos armadas y bajo el más estricto control posible puedan lograr rebelarse y matar a sus vigilantes. Si el recuerdo de estos dos aspectos clave de toda la historia humana, estuvieran más presentes en nuestras mentes, la sociedad represiva y explotadora no encontraría siquiera tiempo para despedirse.

${ }^{20}$ Véase también: Horkheimer y Adorno: Dialéctica de la ilustración, loc. cit., capítulo "Concepto de ilustración."

${ }^{21}$ Véase al respeto Hegel, el filósofo burgués mas avanzado en su filosofía del derecho, donde parte de la idea de que la sociedad burguesa en sí, es incapaz de organizarse a sí misma racionalmente. Hegel trata de resolver este problema con la construcción del Estado, pero al final se queda con el problema sobre qué fundarlo, ya que si se basa democráticamente en la sociedad, está afectado de nuevo por la irracionalidad de esta. Al final de cuentas también Hegel, quién siempre quiere poner la razón encima de todo, traiciona sus principios más profundos y pone por encima del anhelo humano de auto organizarse en una sociedad burguesa, la naturaleza: el príncipe tendrá la última 
Stefan Gandler

Para un concepto de no lineal de Historia

palabra en las decisiones del Estado y es la naturaleza quien lo elije: por ser el primigenio.

${ }^{22}$ La dinámica de la auto conservación es totalitaria en nuestra sociedad, porque es sostenida políticamente por las clases reinantes a pesar de las posibilidades técnicas y económicas (en el sentido enfático) de superar su lógica como dominante.

${ }^{23}$ Es obvio que en ningún sentido estamos de acuerdo con las múltiples interpretaciones que reducen la relación altamente dialéctica entre el materialismo histórico y la teología en este texto de Benjamin, a una simple mixtura aguada de los dos extremos de la contradicción. Pero, así como en Marx, la confrontación dialéctica del materialismo tradicional mecanicista con el idealismo lleva a una nueva forma de materialismo - el materialismo histórico, así la confrontación de este último con la teología, lleva a una nueva forma del materialismo histórico, que todavía no tiene nombre.

${ }^{24}$ Adorno, Theodor W. y Horkheimer, Max: "Elementos del Antisemitismo", capítulo de su libro: Dialéctica de la ilustración, loc. cit., p. 213-250. El tema de la proyección está tratado en la tesis VI de este texto (ibid., p. 230-243). Horkheimer y Adorno distinguen entre "proyección bajo control y su degeneración en falsa proyección" (ibid. p. 232).

${ }^{25}$ “No hay otra cosa que haya corrompido más a la clase trabajadora alemana que la idea de que ella nada con la corriente. El desarrollo técnico era para ella el declive de la corriente con la que creía estar nadando. De allí no había más que un paso a la ilusión de que el trabajo en las fábricas, que sería propio de la marcha del progreso técnico, constituye de por sí una acción política. Bajo una figura secularizada, la antigua moral protestante del trabajo celebraba su resurrección entre los obreros alemanes." (BENJ AMIN, 2008, tesis XI, p. 46.)

${ }^{26}$ Así como ciertas frases del Manifiesto del partido comunista que se suelen citar en este contexto, en donde Marx y Engels hablan de la inevitable victoria del proletariado.

${ }^{27}$ Karl Marx, El capital, Crítica de la economía política. Libro primero. El proceso de producción de capital, tomo I, v. 2. Trad. Pedro Scaron. México, Siglo XXI, 1975, capítulo 13: "Maquinaria y gran industria", sobre todo el subcapítulo 6: "La teoría de la compensación, respecto a los obreros desplazados por la maquinaria", p. 533-544.

${ }^{28} \mathrm{El}$ nacionalsocialismo tiene una doble cara: ideológicamente se presenta como el movimiento de regreso a lo perdido por la 'modernización desde afuera', lo que coincide con su lema de 'Blut und Boden' [sangre y territorio]. Se presenta como la fuerza política y social que frena todo lo que intenta modernizar en lo cultural, social y político a Alemania. Al mismo tiempo es la fuerza política que posibilita, con sus métodos autoritarios una aceleración de los procesos de modernización económica como nunca antes y nunca después se había logrado en Alemania. La predominancia por ejemplo de la industria química alemana en grandes partes del mundo, está basada en la monopolización llevada a cabo con toda la violencia que se consideraba necesaria. Franz Neumann, uno de los autores más relevantes de la Escuela de Frankfurt, analiza en su libro Behemoth. Pensamiento y acción en el Nacional Socialismo la estructura del sistema nacionalsocialista y detecta que está construido sobre cuatro pilares que tienen casi completa autonomía en sus respectivos ámbitos: el ejército, la economía, el partido nacionalsocialista y el aparto burocrático estatal. El 'Führer' sólo intervino cuando los cuatro grupos chocaban abiertamente, lo que casi nunca sucedió. Esta estructura le permite al nacionalsocialismo organizarse en la descrita contradicción sin mayores problemas. Sería entonces sumamente simplificador, ver únicamente la parte de la ideología retrógrada del nazismo, sin ver que en la esfera de la razón instrumental era altamente progresista o modernizadora. En este sentido el nacionalsocialismo no solamente era aun posible, como se dice 
dentro de la lógica que Benjamin critica, sino incluso no hubiera sido posible en tiempos anteriores. (Véase Franz Neumann, Behemoth. Pensamiento y acción en el Nacional Socialismo, loc. cit.).

${ }^{29}$ Sobre la distinción entre mito y concepto de revolución véase también: Bolívar Echeverría, "Postmodernismo y cinismo". En: B.E., Las ilusiones de la modernidad, México, Universidad Nacional Autónoma de México/El Equilibrista, 1995, p. 39-54.

${ }^{30}$ Trad. aquí de Stefan.Gandler. Original: “Marx sagt, die Revolutionen sind die Lokomotiven der Weltgeschichte. Aber vielleicht ist dem gänzlich anders. Vielleicht sind die Revolutionen der Griff des in diesem Zuge reisenden Menschengeschlechts nach der Notbremse."

${ }^{31}$ Benjamin insiste también en la necesidad de conocer la historia posterior, para poder entender un acontecimiento histórico ( $\mathrm{y}$ cada texto es también una forma muy específica de un acontecimiento): "Fustel de Coulanges le recomienda al historiador que quiera revivir una época que se quite de la cabeza todo lo que sabe del curso ulterior de la historia. Mejor no se podría identificar al procedimiento con el que ha roto el materialismo histórico." (BENJ AMIN, 2008, tesis VII, p. 41.)

${ }^{32}$ Conversación del autor con Claude Lanzmann, Frankfurt / Main, 14 de enero 2002.

${ }^{33} \mathrm{No}$ es casual que el público en todos los paises donde hasta ahora se proyectó la película se ríe cuando Yehuda Lerner, el testigo y actor de la insurrección, cuenta que el plan de la rebelión se basó en gran medida sobre la puntualidad de los guardias alemanes en el campo de exterminio Sobibor. Mientras que en las dos proyecciones que la película tenía hasta ahora en Alemania, nadie se reía durante este pasaje. No es solamente por una tal vez más grande distancia personal hacia los guardias alemanes, sino también, porque hay una mayor distancia hacia la ideología de la puntualidad, que en Alemania tiene su bastión más fuerte. Esta ideología expresa a su vez el grado de ingenuidad que existe en la vida cotidiana, donde hay una confianza ilimitada en el avanzar del tiempo y en la bondad y verdad que este avanzar implica según el dominante ethos realista.

${ }^{34}$ Sólo en este sentido la frase 'Cuando está más obscuro amanece', tiene sentido.

${ }^{35}$ Véase: "la fe ciega de esos políticos en el progreso, la confianza en su 'base de masas' y, por último, su servil inserción en un aparato incontrolable no han sido más que tres aspectos de la misma cosa." (BENJ AMIN, 2008, tesis X, p. 45.)

${ }^{36}$ Véase: "La sociedad sin clases no es la meta final del progreso en la historia, sino su interrupción, tantas veces fallida y por fin llevada a efecto." (Walter Benjamin, "Tesis sobre la historia. Apuntes, notas y variantes". En: W.B., Tesis sobre la historia, loc. cit., p. 61-118, aquí: "tesis XVII A", p. 68-70. Véase también: Walter Benjamin, "Sobre el concepto de historia", loc. cit., tesis XVIII, p. 56, nota del editor 5.) Original: "Die klassenlose Gesellschaft ist nicht das Endziel des Fortschritts in der Geschichte, sondern dessen oft mißglückte, endlich bewerkstelligte Unterbrechung." (Walter Benjamin, "Anmerkungen zu den Thesen über den Begriff der Geschichte", loc. cit., p. 1231.)

${ }^{37}$ Esto incluye por supuesto también grupos que numéricamente no son minoritarios, pero en cuestión de poder político o económico lo sean, véase el caso del patriarcado y del apartheid.

${ }^{38}$ Bolívar Echeverría, “El Ethos Barroco”. En: B.E. (Ed.). Modernidad, mestizaje cultural, ethos barroco. México, Universidad Nacional Autónoma de México/El Equilibrista, 1994, p. 13-36, aquí: p. 26.

39 “No hay otra cosa que haya corrompido más a la clase trabajadora alemana que la idea de que ella nada con la corriente." (BENJ AMIN, 2008, tesis XI, p. 46.) 